\title{
Mistral and Tramontane wind speed and wind direction patterns in regional climate simulations
}

\author{
Anika Obermann ${ }^{1} \cdot$ Sophie Bastin $^{2} \cdot$ Sophie Belamari $^{3} \cdot$ Dario Conte $^{4} \cdot$ \\ Miguel Angel Gaertner ${ }^{5}$ Laurent $\mathbf{L i}^{6} \cdot$ Bodo Ahrens $^{1}$
}

Received: 1 September 2015 / Accepted: 18 February 2016 / Published online: 12 March 2016

(c) The Author(s) 2016. This article is published with open access at Springerlink.com

\begin{abstract}
The Mistral and Tramontane are important wind phenomena that occur over southern France and the northwestern Mediterranean Sea. Both winds travel through constricting valleys before flowing out towards the Mediterranean Sea. The Mistral and Tramontane are thus interesting phenomena, and represent an opportunity to study channeling effects, as well as the interactions between the atmosphere and land/ocean surfaces. This study investigates Mistral and Tramontane simulations using five regional climate models with grid spacing of about $50 \mathrm{~km}$ and smaller. All simulations are driven by ERA-Interim reanalysis data. Spatial patterns of surface wind, as well as wind development and error propagation along the wind tracks from inland France to offshore during Mistral and Tramontane events, are presented and discussed. To
\end{abstract}

This paper is a contribution to the special issue on Med-

CORDEX, an international coordinated initiative dedicated to the multi-component regional climate modelling (atmosphere, ocean, land surface, river) of the Mediterranean under the umbrella of HyMeX, CORDEX, and Med-CLIVAR and coordinated by Samuel Somot, Paolo Ruti, Erika Coppola, Gianmaria Sannino, Bodo Ahrens, and Gabriel Jordà.

Anika Obermann

obermann@iau.uni-frankfurt.de

1 Institut für Atmosphäre und Umwelt, Goethe Universität Frankfurt, Altenhöferallee 1, 60438 Frankfurt am Main, Germany

2 LATMOS/IPSL, 11 bd d'Alembert, 78280 Guyancourt, France

3 CNRM/GAME, Météo-France/CNRS, Toulouse, France

4 CMCC, Via Augusto Imperatore 16, 73100 Lecce, Italy

5 UCLM, AVDA. CARLOS III, S/N E45071, Toledo, Spain

6 LMD/UPMC/CNRS, 4 Place Jussieu, 75005 Paris, France disentangle the results from large-scale error sources in Mistral and Tramontane simulations, only days with well simulated large-scale sea level pressure field patterns are evaluated. Comparisons with the observations show that the large-scale pressure patterns are well simulated by the considered models, but the orographic modifications to the wind systems are not well simulated by the coarse-grid simulations (with a grid spacing of about $50 \mathrm{~km}$ ), and are reproduced slightly better by the higher resolution simulations. On days with Mistral and/or Tramontane events, most simulations underestimate (by $13 \%$ on average) the wind speed over the Mediterranean Sea. This effect is strongest at the lateral borders of the main flow-the flow width is underestimated. All simulations of this study show a clockwise wind direction bias over the sea during Mistral and Tramontane events. Simulations with smaller grid spacing show smaller biases than their coarse-grid counterparts.

Keywords Regional climate models $\cdot$ Evaluation $\cdot$ Model intercomparison $\cdot$ Mistral $\cdot$ Tramontane $\cdot$ Bayesian network

\section{Introduction}

The Mistral and Tramontane are mesoscale winds in the Mediterranean region that travel through valleys in southern France. The cold and dry Mistral blows from the north to northwest, and travels down the Rhône valley, between the Alps and Massif Central, which opens to the Gulf of Lion. The Tramontane travels the Aude valley between the Massif Central and Pyrenees. Both valleys (areas outlined in blue in Fig. 1) form a constriction before opening towards the Mediterranean Sea, and are therefore interesting areas for studying channeling effects. Over the sea, these winds cause deep-water 
generation, and thus impact the hydrological cycle of the Mediterranean Sea (Schott et al. 1996; Béranger et al. 2010). Accurate forecasting of wind speeds is important for assessing the risk of damage from strong winds, to evaluate possible sites for wind energy production, and many other purposes. The Mistral and Tramontane occur in similar synoptic situations, and consequently often occur at the same time (Georgelin et al. 1994; Guenard et al. 2005). They are most likely to occur in winter (Jacq et al. 2005)

In this study, 9 years (2000-2008) of surface wind simulations using five regional climate models were evaluated. Simulations driven by ERA-Interim at several resolutions were conducted within the Med-CORDEX project (Ruti et al. 2015) and HyMeX programme (Drobinski et al. 2014). The grid spacings of the simulations $\left(0.44^{\circ}\right.$ and smaller) are appropriate for modeling mesoscale winds such as the Mistral and Tramontane, which can extend several $100 \mathrm{~km}$ over the Mediterranean Sea. However, the constrictions and channeling effects in the Rhône and Aude valleys have too complex topography to be well represented in $0.44^{\circ}$ simulations.

To the authors' knowledge, this is the first multi-model evaluation of regional climate models in terms of Mistral and Tramontane events covering several years. Several case studies have been performed on Mistral events (Guenard et al. 2005; Drobinski et al. 2005) and their interaction with sea breezes (Bastin et al. 2006) and heavy precipitation events (Berthou et al. 2014, 2015). Tramontane events have also been studied (Drobinski et al. 2001). An introduction to other phenomena connected to the Mistral and Tramontane is given in Drobinski et al. (2005) and references therein.

This study surveys the Mistral and Tramontane spatial patterns as well as the error propagation along the valleys and over the Mediterranean Sea. Errors that occur far up in the valleys might increase or counteract errors that occur further downstream. Three possible sources of errors are surveyed: large-scale pressure patterns, processes in the valleys, and processes above the Mediterranean Sea. Surface wind speed and direction (i.e., of winds $10 \mathrm{~m}$ above ground), as well as sea level pressure over southern France and the western Mediterranean Sea, are compared to gridded observation data sets and reanalysis data. To obtain an objective comparison, and to exclude days on which the large-scale sea level pressure fields are not well simulated, the days that are used for comparison are determined by a classification algorithm.

This paper is structured as follows. The measurement and simulation data are discussed in Sects. 2 and 3. Then, the methods used are explained in Sect. 4 , followed by the results in Sect. 5 and a discussion in Sect. 6. The last section contains a summary and conclusion.

\section{Observational data}

Mistral and Tramontane time series and two gridded observational surface wind data sets are used in this study, one for evaluation over France, and one for evaluation over the Mediterranean Sea.

\subsection{Mistral and Tramontane areas}

Figure 1 shows the western Mediterranean Sea area. Altitudes and distances to the coast are used to identify Mistral and Tramontane-affected regions in France and over the Mediterranean Sea, as explained below.

This study deals with areas below $600 \mathrm{~m}$ altitude in the Rhône and Aude valleys, which are less than $270 \mathrm{~km}$ away from the coast of the Mediterranean Sea (outlined in blue in Fig. 1). The altitude information came from ETOPO1, a 1 arc-minute global relief model of Earth's surface (Amante and Eakins 2009), interpolated to a $0.1^{\circ}$ grid. The distance to the coast was calculated for each land grid cell within this area. The narrowest parts of both valleys are about $40 \mathrm{~km}$ wide, which is close to the grid spacing of the $0.44^{\circ}$ simulations. The area outlined in gray in Fig. 1 indicates the part of the Mediterranean Sea that is of interest in this study. It includes the main parts of the western Mediterranean Basin that are influenced by Mistral and Tramontane winds. The areas south of the Balearic Islands and

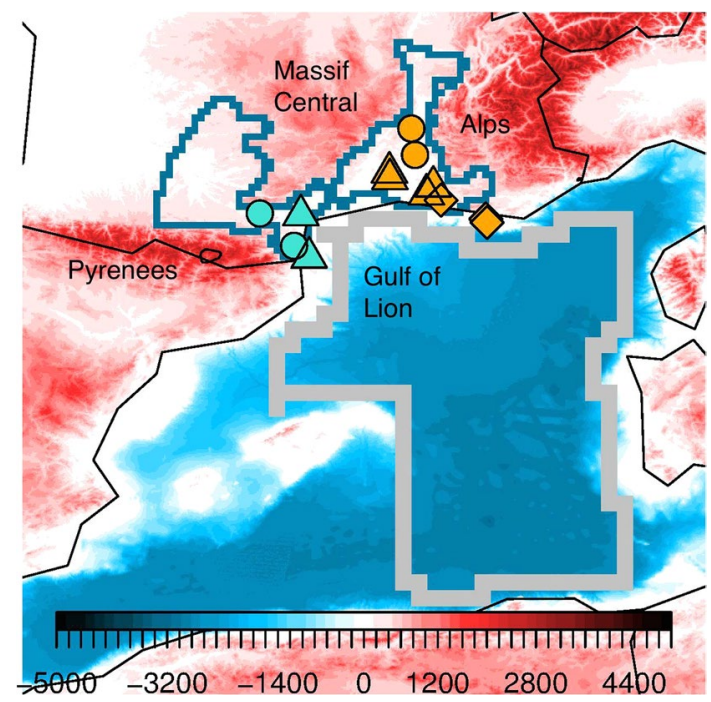

Fig. 1 Orography (shaded in red) and bathymetry (shaded in blue) from ETOPO1 (Amante and Eakins 2009) in Mistral and Tramontane regions (in m). Analysis areas in Mistral and Tramontane valleys (outlined in blue) and Mediterranean Sea (outlined in gray), location of stations for gust time series in Mistral area (orange symbols) and Tramontane area (turquoise symbols) in the valleys (circles), in the plains (triangles), and close to the coast (squares) 
southeast of Corsica and Sardinia were excluded because the islands modify the wind speed by changes in surface roughness and orographic effects.

\subsection{Mistral and Tramontane time series}

The daily gust time series in the Mistral and Tramontane areas provide data of gusts from the dominant Mistral and Tramontane direction, with velocities greater than $16 \mathrm{~m} / \mathrm{s}$, observed at each station. Jacq et al. (2005) used this threshold to identify Mistral days. Gusts above this value have been found to cause damage to forests in complex terrain (Jungo et al. 2002; Schmidtke and Scherrer 1997). Gust observations from 13 stations are available for the period 2000-2008. Table 1 indicates the station locations, and the Mistral or Tramontane wind direction at each station. Figure 1 shows the locations of the stations.

The days of the period from 2000-2008 were partitioned into four classes depending on which wind system occurred: Neither Mistral nor Tramontane ("non-M/T days"), only Mistral, only Tramontane, or Mistral and Tramontane ("M/T days"). A day was considered an observed Mistral day if gusts from the directions given in Table 1 were observed at least at one station in each of the following parts of the Mistral area:

- Rhône valley at Montélimar or Orange (orange circles in Fig. 1)

- Plains at Nimes-Courbessac, Nimes-Garons, Istres, or Salon (orange triangles)

Table 1 List of stations used for time series generation

\begin{tabular}{llll}
\hline Station Name & Longitude $\left({ }^{\circ} \mathrm{E}\right)$ & Latitude $\left({ }^{\circ} \mathrm{N}\right)$ & $\begin{array}{l}\text { Direction of } \\
\text { Gusts }\left({ }^{\circ}\right)\end{array}$ \\
\hline Mistral & & & \\
Montélimar & 4.75 & 44.56 & $320-040$ \\
Orange & 4.81 & 44.14 & $320-030$ \\
Nimes- & 4.40 & 43.86 & $320-040$ \\
$\quad$ Courbessac & & & \\
Nimes-Garons & 4.41 & 43.76 & $320-040$ \\
Istres & 4.99 & 43.51 & $330-010$ \\
Salon & 5.10 & 43.64 & $330-010$ \\
Marignane & 5.22 & 43.42 & $330-010$ \\
Toulon & 5.93 & 43.12 & $260-340$ \\
Cap Cepet & 5.95 & 43.07 & $260-340$ \\
Tramontane & & & \\
Carcassonne & 2.35 & 43.21 & $260-320$ \\
Perpignan & 2.90 & 42.70 & $300-360$ \\
Cap Bear & 3.13 & 42.52 & $300-360$ \\
Narbonne & 3.00 & 43.18 & $260-320$ \\
\hline
\end{tabular}

- Coast at Marignane, Toulon, or Cap Cepet (orange squares).

For an observed Tramontane day, gusts must have been present at least at one station in each of two areas:

- Carcassonne or Perpignan (turquoise circles in Fig. 1)

- Cap Bear or Narbonne (turquoise triangles).

These strong criteria for distinction was used to ensure that only days with contiguous flow stretching along the entire valley and reaching the coast were taken into account, while days with an interfering sea breeze or valley winds on smaller scales were omitted. Table 2 shows the resulting numbers of days for each class.

Table 3 shows the Pearson correlation coefficient for indicator time series of days with Mistral only (M), Tramontane only (T), both at same time (B) and none of both (N). For binary variables, this coefficient-also called phi-coefficent - can not neccessarily reach $1(-1)$ for perfect (anti-)correlation. The maximum possible correlation depends on the number of TRUE and FALSE values in both time series to be correlated (Warrens 2008). Therefore, the correlation values of Mistral only cases (66 in the time period of this study) are generally lower than those of the other situations. The Pearson correlation coefficient is positive (negative) if a situation occurs more (less) often after another situation than expected for a random distribution of N, M, T, and B situations. All four situations are positively correlated with the same time series shifted by one day (diagonal in Table 3), but for Mistral this correlation is very low. Mistral situations are preceded by a day with neither Mistral nor Tramontane in $75.76 \%$ of the cases and followed by a day with both Mistral and Tramontane

Table 2 Numbers of days with Mistral and Tramontane occurrence

\begin{tabular}{lccr}
\hline 2000-2008 & Tramontane & No Tramontane & \\
\hline Mistral & 565 & 66 & 631 \\
No Mistral & 844 & 1813 & 2657 \\
& 1409 & 1879 & 3288 \\
\hline
\end{tabular}

Table 3 Pearson correlation coefficient for observed time series of days with Mistral only (M), Tramontane only (T), both at same day (B) and none of both $(\mathrm{N})$

\begin{tabular}{lllll}
\hline & $\mathrm{N}(t-1)$ & $\mathrm{M}(t-1)$ & $\mathrm{T}(t-1)$ & $\mathrm{B}(t-1)$ \\
\hline $\mathrm{N}(t)$ & +0.46 & -0.06 & -0.16 & -0.40 \\
$\mathrm{M}(t)$ & +0.06 & +0.04 & -0.05 & -0.03 \\
$\mathrm{~T}(t)$ & -0.27 & -0.01 & +0.20 & +0.12 \\
$\mathrm{~B}(t)$ & -0.32 & +0.08 & -0.01 & +0.40 \\
\hline
\end{tabular}


in $37.88 \%$ of the cases. Days with both winds occuring are often followed by Tramontane only days (37.35 \%) or days with both winds (49.91\%).

\subsection{SAFRAN data set}

The "Système d'Analyse Fournissant des Renseignements Atmosphériques à la Neige" (analysis system to provide data for snow models, SAFRAN) is a reanalysis product over France (Vidal et al. 2010; Quintana-Seguí et al. 2008). It consists of a gauge-based analysis system utilizing an optimal interpolation method with 615 climatically homogeneous zones covering France. SAFRAN includes information on variables such as precipitation, mean air temperature, and wind speed — but not wind direction — which are calculated every $6 \mathrm{~h}$. For this analysis, daily mean surface wind speed data on a $0.1^{\circ}$ grid for the period 2000-2008 are used.

\subsection{QuikSCAT data set}

QuikSCAT is a satellite instrument measuring wind speed and wind direction over the oceans. It was operational from 1999 to 2009. Full years of data are available for 20002008 on a $25 \mathrm{~km}$ grid. The QuikSCAT technical mission requirements included wind speed measurement accuracies of $2 \mathrm{~m} / \mathrm{s}$ for wind speeds between 3 and $20 \mathrm{~m} / \mathrm{s}$, and an accuracy of $10 \%$ for wind speeds between 20 and $30 \mathrm{~m} / \mathrm{s}$ (Lungu et al. 2006). The wind direction ambiguity was $20^{\circ}$. Surface wind speeds and wind directions in the area of interest of this study were retrieved up to twice a day, around 6 a.m. and 6 p.m. local time. To compute the daily means, the two daily measurements at the same location are averaged. Data contaminated by rain events are omitted.

QuikSCAT has been used for wind speed analysis in the Mediterranean (e.g., Accadia et al. 2007; Ruti et al. 2008), as well as in many other regions (Dorman et al. 2013; Risien and Chelton 2006). QuikSCAT data have been validated with buoy data in the Gulf of Lion for the period 2000-2005 (Accadia et al. 2007; Ruti et al. 2008), showing a bias of about $0.4-0.9 \mathrm{~m} / \mathrm{s}$, and an RMSE of about $1.5 \mathrm{~m} / \mathrm{s}$. Ruti et al. (2008) found the bias of QuikSCAT compared to buoys to be higher for high wind speeds. This is consistent with results for the time interval of this study (not shown).

\subsection{Observed daily mean surface wind speed}

Figure 2 shows the mean surface wind speed in 2000-2008 calculated from SAFRAN data over France and QuikSCAT data over the western Mediterranean Sea, sorted according to the Mistral and Tramontane occurrences in the observed time series described in Sect. 2.2. On non-M/T days, the mean wind speed over France is less than 5, and $4-8 \mathrm{~m} / \mathrm{s}$

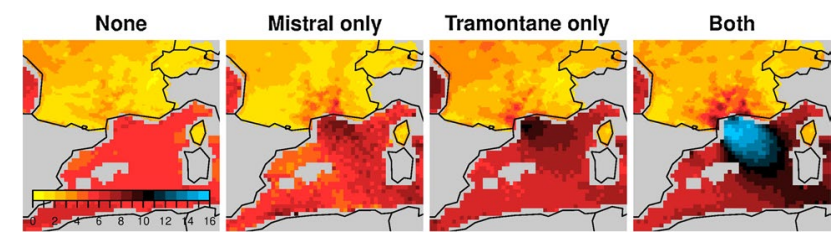

Fig. 2 Mean wind speed $(\mathrm{m} / \mathrm{s})$ from SAFRAN and QuikSCAT data on days in 2000-2008 with neither Mistral nor Tramontane (left), only Mistral (second from left), only Tramontane (third from left) and Mistral and Tramontane together (right). The number of days in each category is given in Table 2

over the Mediterranean Sea. On Mistral days, the mean wind speed in Southern France (mainly in the Rhône valley) is greater than $4 \mathrm{~m} / \mathrm{s}$. The wind speed in the eastern Gulf of Lion also increases, and reaches $8-12 \mathrm{~m} / \mathrm{s}$. On Tramontane days, the mean wind speed in the Aude valley reaches values of $4-8 \mathrm{~m} / \mathrm{s}$, and in the Gulf of Lion, it reaches values greater than $10 \mathrm{~m} / \mathrm{s}$. If both Mistral and Tramontane winds occur simultaneously, the wind speed in southern France and the Mediterranean Sea increases to more than $15 \mathrm{~m} / \mathrm{s}$.

\section{Simulations}

All the regional climate simulations in this study are part of the Med-CORDEX framework (Ruti et al. 2015) and the HyMeX programme (Drobinski et al. 2014). Simulations were performed on the Med-CORDEX domain covering the Mediterranean Sea and Black Sea, as well as the surrounding land areas, with ERA-Interim as the driving data. For each model within this study, a simulation on a $0.44^{\circ}$ grid is available. For most models, a simulation with a higher resolution (i.e. a more dense grid spacing of 0.088$0.22^{\circ}$ ) is available as well. Some basic properties of the models are described in this section. The simulations are identified by the name of the institution where the simulation was performed, followed by the name of the model employed.

\subsection{ERA-Interim}

In this study, ERA-Interim is used as a reference for classifying days based on the occurrence of Mistral and Tramontane-permitting sea level pressure patterns, and is also used as the forcing for all the regional climate simulations within this study. ERA-Interim is a reanalysis product (Dee et al. 2011) calculated with a resolution of about $80 \mathrm{~km}$. ERA-Interim data for sea level pressures, surface wind speeds, and surface wind directions were obtained from the European Centre for Medium-Range Weather Forecasts (ECMWF) database. 


\subsection{Regional climate models}

ALADIN is the limited-area version of ARPEGE, a global spectral model which is used operationally at Météo-France. The ALADIN simulations in this study were performed by the Centre National de Recherches Météorologiques (CNRM) with ALADIN version 5.2 on $0.44^{\circ}$ and $0.11^{\circ}$ grids. A detailed description of the model can be found in Colin et al. (2010) and Herrmann et al. (2011), who studied the influence of the model configuration on wind speed over the Mediterranean Sea.

The Weather Research and Forecasting (WRF) model developed by the National Center for Atmospheric Research (NCAR) is the only model in this study that is nudged to wind, temperature, and humidity ERA-Interim fields above the boundary layer. Another notable point is that no subgrid-scale orography is considered in this version of WRF. Within this study, WRF simulations with $0.44^{\circ}$ and $0.18^{\circ}$ grid spacing were performed by Institut Pierre Simon Laplace (IPSL) using WRF 3.1.1. An introduction to WRF 3 is given in Skamarock et al. (2008). More details about the configuration and set of parameterizations can be found in Flaounas et al. (2013) or Stéfanon et al. (2014).

PROMES simulations with $0.44^{\circ}$ and $0.22^{\circ}$ grid spacing were performed by Universidad de Castilla-La Mancha (UCLM), where the model also was developed. The PROMES model is described in Domínguez et al. (2010).

The COSMO-CLM (CCLM) model (Rockel et al. 2008; Kothe et al. 2014) is the climate version of the COSMO model, which is used by the German Weather Service for operational weather forecasts. Simulations were performed by Goethe Universität Frankfurt (GUF) with CCLM 4-8-18 on $0.44^{\circ}$ and $0.088^{\circ}$ grids, and by Centro Euro-Mediterraneo sui Cambiamenti Climatici (CMCC) with CCLM 4-819 on a $0.44^{\circ}$ grid.

The LMDZ simulation with $0.44^{\circ}$ grid spacing was performed by Laboratoire de Météorologie Dynamique (LMD), where the model was developed. The model version LMDZ 4 is described in Hourdin et al. (2006).

\subsection{Roughness length parameterizations}

The roughness length, $z_{0}$, is a key parameter for surface wind parameterizations. Over land surfaces, it depends on the land use and annual cycle of vegetation (Lawrence and Slingo 2004a, b), as well as sub-grid scale orography (Georgelin et al. 1994). The $z_{0}$ calculation differs in regional climate models. The roughness length varies depending on waves-and therefore on wind speed-over the sea surface. A classical parameterization of sea surface roughness was introduced by Charnock (1955). The Charnock formula is $z_{0}=\frac{\alpha}{g} \cdot u_{*}^{2}$

Here, $\alpha$ denotes the Charnock parameter, $g$ the gravity constant, and $u_{*}$ the friction velocity. The numerical value of $\alpha$ varies between models. GUF-CCLM uses the rather small value of $\alpha=0.0123$, while the value used by UCLM-PROMES is almost three times as large $(\alpha=0.032)$. CNRM-ALADIN $(\alpha=0.021)$ and IPSLWRF ( $\alpha=0.0185$ ) use values in between these extremes. To avoid a zero roughness length, the Charnock formula is slightly modified in numerical calculations. A constant value of $1.59 \times 10^{-5} \mathrm{~m}$ is added to the roughness length, e.g., in IPSL-WRF, while CCLM uses the maximum value of $u_{*}$ or free convection scaling velocity $w_{*}$ (whichever is larger) in the Charnock formula (Doms et al. 2011). Several versions of this formula have been discussed (e.g., Powell et al. 2003; Donelan et al. 1993), taking into account further effects, such as those of fetch (Lange et al. 2001), seafloor depth (Jiménez and Dudhia 2014), spray (Andreas 2004; Golbraikh and Shtemler 2013), and swell (Potter 2015). Cavaleri et al. (2012) give an overview of the influence of waves on air-sea exchanges.

The friction velocity $u_{*}$ depends on momentum fluxes at the surface $\tau_{s}$ and density $\rho$ :

$u_{*}=\sqrt{\frac{\tau_{s}}{\rho}}$

Through $\tau_{s}$, the friction velocity depends on the roughness length and needs to be calculated iteratively. The procedure of calculating $u_{*}$ varies between models.

\subsection{Spatial and temporal interpolation of simulation data sets}

All simulated sea level pressure data sets were bilinearinterpolated to a common $0.25^{\circ}$ grid, while surface wind data sets were bilinear-interpolated to the SAFRAN grid for evaluation over France, and to the QuikSCAT grid for evaluation over the Mediterranean Sea. The daily means of simulation data were optained directly from the MedCORDEX data base. Thus, the simulation daily means are means over the whole day, while QuikSCAT daily means are the average of two measurements per day.

\section{Methods}

The main focus of this study is the evaluation of surface wind patterns during Mistral and Tramontane events. Therefore, the days of interest are those on which both the simulation and observation agreed on whether or not an M/T occurred. Mistral and Tramontane are driven by large 

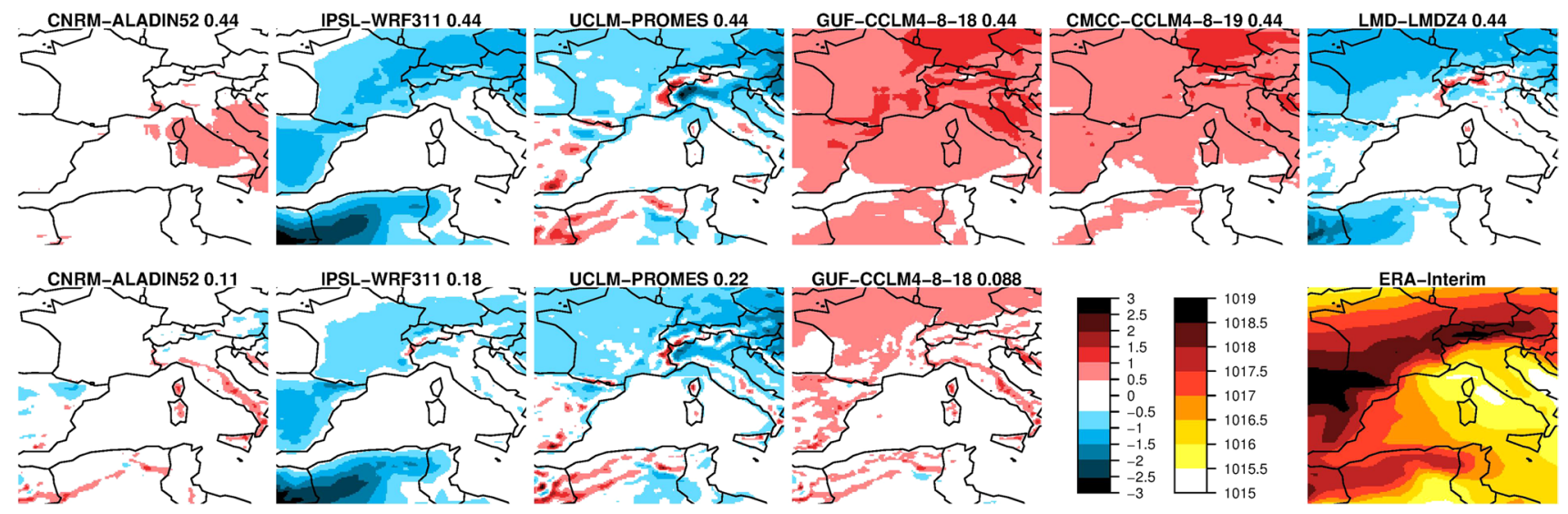

Fig. 3 Sea level pressure bias of simulations and mean sea level pressure of ERA-Interim in 2000-2008 (hPa). Left color scale is for the bias plots, right color scale is for the ERA-Interim plot

scale flow settings that favor the channeling of winds in the Rhône and Aude valleys. A pressure low in the Genoa area is a known feature of these events. Therefore, one way to identify Mistral and Tramontane days could be using the minimum sea level pressure in the Genoa area. When regarding the 631 (1409) days with lowest ERA-Interim sea level pressure in this area in 2000-2008 as Mistral (Tramontane) days, the agreement with the observed M/T time series is $55 \%$. To improve this value, an alternative way was used to identify M/T days from sea level pressure fields: A classifying algorithm, including Empirical Orthogonal Function (EOF) analysis and a Bayesian network, was used to decide on which days the large-scale sea level pressure fields were well represented in the simulations, and thus identify the large-scale $\mathrm{M} / \mathrm{T}$ candidates. An introduction to EOF analysis can be found in, e.g., Storch and Zwiers (2001). For an introduction to Bayesian networks, see e.g., Scutari (2010).

\subsection{EOF analysis}

To compare the large-scale features, an EOF analysis of the ERA-Interim daily mean sea level pressure field in the area $-20-20^{\circ}$ East and $25-55^{\circ}$ North are carried out for the period 2000-2008. This area is chosen because it includes the Mistral and Tramontane regions, as well as the surrounding areas, which are most important for the development of a Mistral and Tramontane-permitting pressure system, while other parts (especially the eastern region of the Med-CORDEX domain) would mainly add noise to the EOFs.

\subsubsection{EOF patterns}

Figure 3 shows the mean sea level pressure in the western Mediterranean region for ERA-Interim, and the simulation biases with respect to ERA-Interim. All biases are

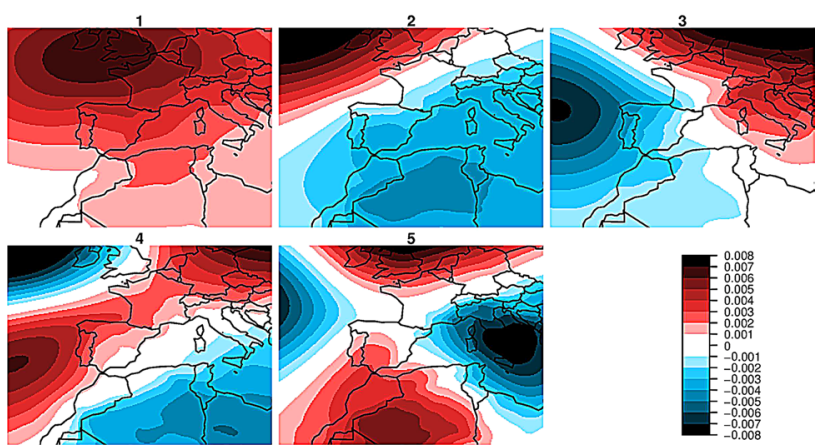

Fig. 4 First five EOFs calculated from ERA-Interim daily mean sea level pressure fields 2000-2008 (arbitrary units)

calculated as simulation minus reference. The simulations done with IPSL-WRF, UCLM-PROMES, and LMDLMDZ show a mostly negative bias, while the biases of both GUF-CCLM and CMCC-CCLM are mostly positive. CNRM-ALADIN has a positive bias at the Mediterranean Sea, but a negative bias in parts of Europe and Africa.

Figure 4 shows the first five EOFs from ERA-Interim. The first EOF explaines $43.15 \%$ of the variance and features a high pressure system over southern England. The second and third EOFs show dipole patterns and explain 24.80 and $14.28 \%$ of the variance. The fourth and fifth EOFs already feature quadrupole patterns and explain 5.28 and $3.55 \%$ of the variance.

\subsubsection{Principal components}

The principal components (PCs) of the first 100 EOFs were calculated for ERA-Interim (which is the reference data set), as well as for each of the simulation data sets (i.e., simulation data are projected to the reference EOFs). This number of EOFs is chosen because it is high enough 
to cover a large part of the variance $(99.97 \%)$ and sufficiently convenient to work with. A loss-less description of the sea level pressure fields of all 3288 days in the years 2000-2008 would need 3288 EOFs. Additionally, this choice reduces the noise caused by small-scale variations represented by higher-order EOFs.

Figure 5 shows the annual cycle of the first five ERAInterim principal components. The first principal component shows a positive value during winter and a negative or almost zero value during the rest of the year. The second principal component shows an inverse annual cycle with negative values from October till March and positive values from April to September. The higher order principal components show a less pronounced annual cycle. Both the first and second principal component correlate with the Mistral and Tramontane time series, while the third principal component anti-correlates with the Mistral and Tramontane time series.

Figure 6 shows the correlations between the first 20 ERA-Interim principal components and simulated principal components. The first principal component has the highest correlation for all simulations, while the correlation decreases for higher-order principal components.

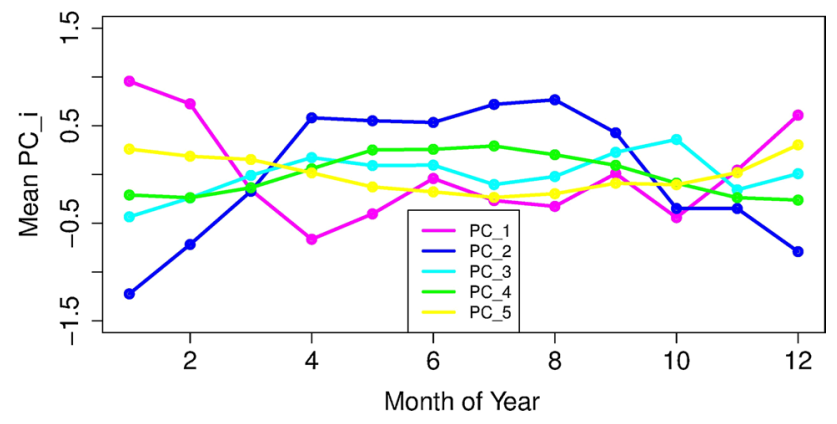

Fig. 5 Monthly means of first five ERA-Interim principal components

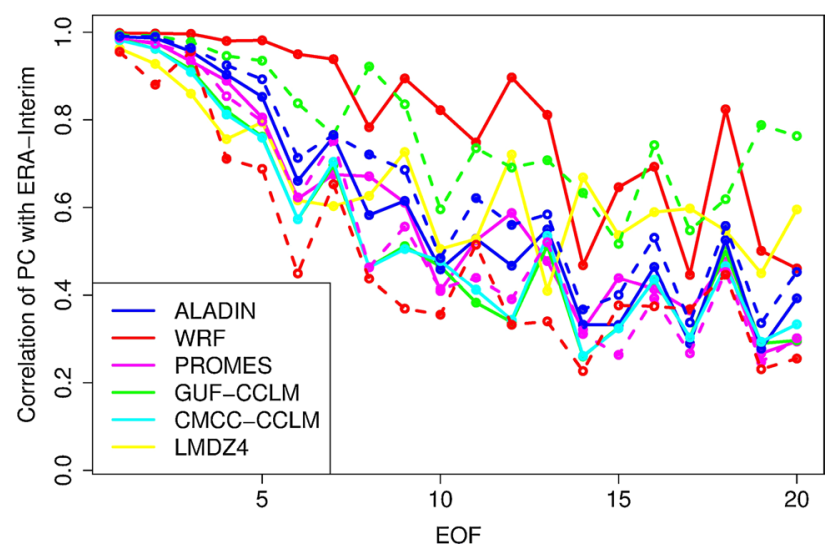

Fig. 6 Correlation of simulation and ERA-Interim principal components. Solid lines indicate $0.44^{\circ}$ runs, dashed lines indicate smaller grid spacing runs

\subsection{Classifying sea level pressure patterns}

The classifying algorithm consists of three parts: preparation of input data, structure learning and training, and output processing.

\subsubsection{Preparation of input data}

Reference and simulation principal components were normalized (indicated by exponent $n$ ) to compensate for different amplitudes and mean values:

$P C_{i}^{n}(t)=\frac{P C_{i}(t)-\mu_{i}}{\sigma_{i}}$

Here, $\mu_{i}$ denotes the mean, and $\sigma_{i}$ the standard deviation of the $i$ th principal component $P C_{i}$. The day is denoted by $t$. The normalization allowed the Bayesian network to assign a realistic weight to all the principal component time series.

\subsubsection{Structure learning and training}

The Bayesian network is trained using the normalized ERA-Interim principal components and the observed time series of Mistral and Tramontane days as training data. The Bayesian network obtained its structure using a hillclimbing algorithm (Tsamardinos et al. 2006). The TRUE/ FALSE time series were transformed to 1 (TRUE) and 0 (FALSE) values. Figure 7 shows the Bayesian network after structure learning. During the training procedure, weights were given to the connections (arcs) between input nodes $P C_{i}$ and the output node $M / T$. Additionally, some arcs might have been removed during training if the Bayesian network did not find a connection between a principal component and the time series.

\subsubsection{Output processing}

After the training, the Bayesian network determines on which days the simulations' sea level pressure fields show a Mistral and Tramontane-permitting pattern. When using a simulation's normalized principal components for one

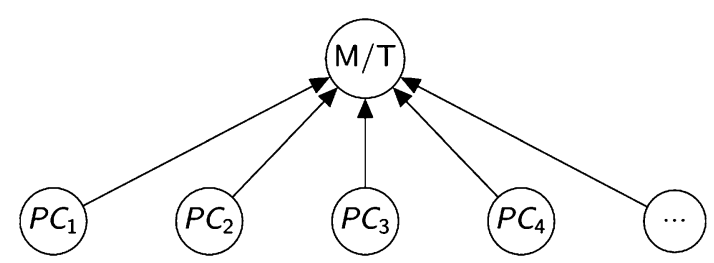

Fig. 7 Structure of the Bayesian network. The normalized principal components (PC) are used as inputs for the lower row of nodes. The upper node $M / T$ denotes the output, a number which can be related to the probability of a $\mathrm{M} / \mathrm{T}$ situation being present or not 
day as input for nodes $P C_{i}$, the trained Bayesian network assigns a score value to node $M / T$. Higher values correlate with an increasing probability of a Mistral or Tramontane event on that day. The transformation from a continuous output variable to a TRUE/FALSE variable was done by keeping the total number of Mistral and Tramontane days in the time interval 2000-2008 the same as that in the observed time series. Therefore, for each simulation, the 631 days with highest Mistral probability and 1409 days with highest Tramontane probability were regarded as Mistral and Tramontane days, respectively (see Table 2).

After the classification procedure, a time series of $\mathrm{M} / \mathrm{T}$ patterns is available for each simulation. It consists of the information of whether or not a Mistral and/or Tramontanepermitting sea level pressure pattern was present in the simulation on that day. In subsequent steps of this discussion, the only days considered are those days on which the time series produced by the classification algorithm and the observed time series agree on whether or not an M/T pattern was present.

\subsubsection{Length of training period}

To verify that the training period 2000-2008 contains enough Mistral and Tramontane cases to reach a sufficient level of training, the observed $\mathrm{M} / \mathrm{T}$ time series and the ERA-Interim principal components are split in two partsthe training data set and the validation data set. The days are randomly chosen to belong to one of the two data sets. The Bayesian network is trained with the training data set. Then, the output of the Bayesian network is compared to observations for both training and validation data set. When using 7 or 8 years of training data, the Bayesian networks performs almost equally well for both the training and the evaluation data set (Fig. 8). Longer training periods have been tested for the years 1981-2010, and do not significantly improve the percentage of correctly predicted patterns (not shown).

\subsection{Wind direction bias and RMSE over the Mediterranean Sea}

To evaluate the simulations in terms of surface wind direction, QuikSCAT was chosen as reference (no gridded wind direction data over France is available). For each grid cell, the average wind direction of the simulation $\left(\beta_{\text {sim }, t}\right)$ and QuikSCAT $\left(\beta_{\text {obs }, t}\right)$ were calculated from zonal $(u)$ and meridional $(v)$ wind speed. Only data points with two measurements per day were taken into account to minimize the effects of land-sea wind systems. The wind direction difference between the simulation and QuikSCAT was calculated for each day $t$ :

$\beta_{t}=\beta_{\text {sim }, t}-\beta_{\text {obs }, t}$

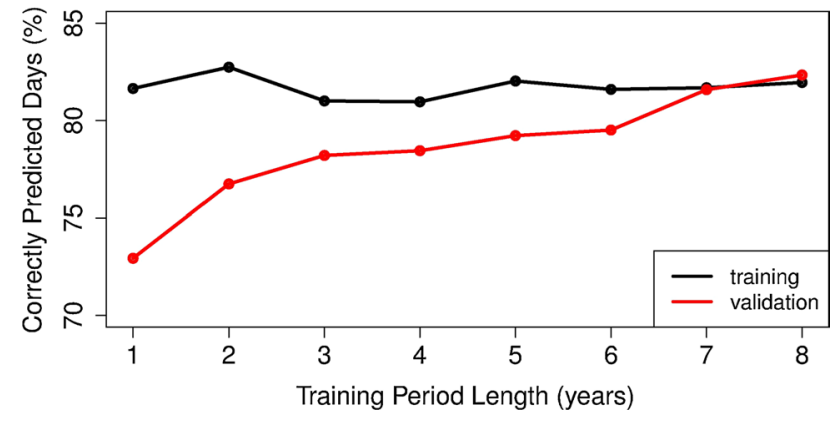

Fig. 8 Percentage of corretly predicted M/T situations from ERAInterim sea level pressure fields as function of training period length for the years 2000-2008. The validation data set consists of all days in this time intervall, which are not included in the training data set

The average of the daily differences is the wind direction bias $\beta_{\text {bias }}$ :

$\beta_{\text {bias }}=\frac{1}{N} \sum_{t=1}^{N} \begin{cases}\beta_{t}, & \left|\beta_{t}\right| \leq 180^{\circ} \\ \left(\left|\beta_{t}\right|-360^{\circ}\right) \cdot \frac{\beta_{t}}{\left|\beta_{t}\right|}, & \left|\beta_{t}\right|>180^{\circ}\end{cases}$

This formula takes into account that the difference in wind direction has to be less than $\pm 180^{\circ}$. The wind direction root mean square error (RMSE) $\beta_{R M S E}$ is calculated accordingly:

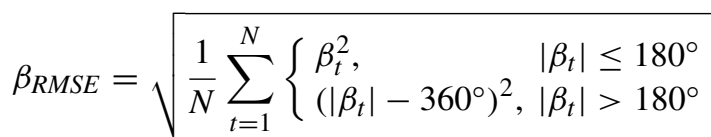

\subsection{Fetch}

Within this study, the evolution of errors along the wind track is of interest. To perform this evaluation over the Mediterranean Sea-where Mistral and Tramontane are not channelled through valleys - a fetch calculation was performed. Fetch in this sense is defined as the distance an air parcel traveled above the sea surface before reaching its current position.

To calculate an estimated fetch from the daily mean wind speed and direction, uncertainties in the exact path of the air parcel have to be taken into account. Therefore, the average fetch of a grid cell with a given daily mean wind direction $\phi$ was calculated in two steps, following the approach for calculating the effective fetch in Lange et al. (2001). In the first step, the distance $d\left(\phi_{i}\right)$ to the next coastal grid cell in each direction was calculated for all directions in $1^{\circ}$ intervals. In the second step, the average fetch of wind coming from direction $\phi$ was calculated by a weighted average of the interval $\phi \pm 90^{\circ}$ :

$\operatorname{fetch}(\phi)=\frac{1}{90} \sum_{\phi_{i}=\phi-90^{\circ}}^{\phi+90^{\circ}}\left[\cos ^{2}\left(\phi-\phi_{i}\right) \cdot d\left(\phi_{i}\right)\right]$ 
Table 4 Number of days with wind systems correctly predicted by Bayesian network

\begin{tabular}{|c|c|c|c|c|c|c|c|c|c|c|c|}
\hline \multirow[t]{2}{*}{ Simulation } & \multirow[t]{2}{*}{ Grid $\left(^{\circ}\right)$} & \multicolumn{2}{|l|}{ None } & \multicolumn{2}{|c|}{ Mistral } & \multicolumn{2}{|c|}{ Tramontane } & \multicolumn{2}{|l|}{ Both } & \multicolumn{2}{|l|}{ Sum } \\
\hline & & Days & $\%$ & Days & $\%$ & Days & $\%$ & Days & $\%$ & Days & $\%$ \\
\hline \multirow[t]{2}{*}{ CNRM-ALADIN } & 0.44 & 1601 & 88.3 & 3 & 4.5 & 486 & 57.6 & 432 & 76.5 & 2522 & 76.7 \\
\hline & 0.11 & 1589 & 87.6 & 10 & 15.2 & 504 & 59.7 & 429 & 75.9 & 2532 & 77.0 \\
\hline \multirow[t]{2}{*}{ IPSL-WRF } & 0.44 & 1611 & 88.9 & 10 & 15.2 & 540 & 64.0 & 439 & 77.7 & 2600 & 79.1 \\
\hline & 0.18 & 1626 & 89.7 & 5 & 7.6 & 514 & 60.9 & 451 & 79.8 & 2596 & 79.0 \\
\hline \multirow[t]{2}{*}{ UCLM-PROMES } & 0.44 & 1585 & 87.4 & 8 & 12.1 & 482 & 57.1 & 410 & 72.6 & 2485 & 75.6 \\
\hline & 0.22 & 1561 & 86.1 & 10 & 15.2 & 469 & 55.6 & 409 & 72.4 & 2449 & 74.5 \\
\hline \multirow[t]{2}{*}{ GUF-CCLM } & 0.44 & 1601 & 88.3 & 10 & 15.2 & 510 & 60.4 & 420 & 74.3 & 2541 & 77.3 \\
\hline & 0.088 & 1546 & 85.3 & 13 & 19.7 & 507 & 60.1 & 403 & 71.3 & 2469 & 75.1 \\
\hline CMCC-CCLM & 0.44 & 1580 & 87.1 & 11 & 16.7 & 493 & 58.4 & 414 & 73.3 & 2498 & 76.0 \\
\hline LMD-LMDZ & 0.44 & 1594 & 87.9 & 8 & 12.1 & 501 & 59.4 & 393 & 69.6 & 2496 & 75.9 \\
\hline ERA-Interim & & 1654 & 91.2 & 12 & 18.2 & 580 & 68.7 & 449 & 79.5 & 2695 & 82.0 \\
\hline Observed time series & & 1813 & - & 66 & - & 844 & - & 565 & - & 3288 & - \\
\hline
\end{tabular}

Table 5 Pearson correlation coefficient for time series of Mistral only (M), Tramontane only (T), both at same day (B) and none of both (N) for GUF-CCLM 4-8-18 at $0.088^{\circ}$

\begin{tabular}{lllll}
\hline & $\mathrm{N}(t-1)$ & $\mathrm{M}(t-1)$ & $\mathrm{T}(t-1)$ & $\mathrm{B}(t-1)$ \\
\hline $\mathrm{N}(t)$ & +0.51 & -0.08 & -0.20 & -0.42 \\
$\mathrm{M}(t)$ & +0.03 & +0.15 & -0.05 & -0.03 \\
$\mathrm{~T}(t)$ & -0.32 & -0.02 & +0.28 & +0.11 \\
$\mathrm{~B}(t)$ & -0.31 & +0.08 & -0.05 & +0.43 \\
\hline
\end{tabular}

\section{Results}

\subsection{Classifying Tramontane and Mistral days}

Table 4 shows the number and percentage of days on which the observed time series and the simulation time series produced by the Bayesian network are in agreement. All the simulation time series agree with the observed time series on more than $74 \%$ of the days. ERA-interim, which was used as training data, shows the highest percentage of correctly predicted days ( $82 \%)$. IPSL-WRF shows the highest percentage of correct days of all the simulations. The observed time series includes 1813 non-M/T days. The classifying algorithm finds a non-M/T pattern on more than $85 \%$ of these days in all the simulations. Non-M/T days are identified correctly in 85.3-91.2\% of the cases. The rare Mistral-only events are identified correctly in less than $20 \%$ of the days, while the numerous Tramontane-only events are identified correctly in $55.6-64.0 \%$ of the cases. $\mathrm{M} / \mathrm{T}$ patterns are identified correctly in $69.6-79.8 \%$ of the cases. This leads to a false alarm ratio (either Mistral or Tramontane or both winds were predicted, but none of them observed) of $8.8-14.7 \%$ of the non-M/T cases, which corresponds to $4.9-8.1 \%$ of all days. Only M/T and non-M/T days on which the simulation and observed time series agree on the occurring wind systems are taken into account in subsequent steps of this study.

Table 5 shows the Pearson correlation coefficient for $\mathrm{M} / \mathrm{T}$ time series as Table 3, but for GUF-CCLM 4-8-18 at $0.088^{\circ}$. The other simulations show similar Pearson correlation coefficients for most cases, while the value for the persistence of Mistral only days varies between simulations. CNRM-ALADIN $0.44^{\circ}$, IPSL-WRF $0.18^{\circ}$, and ERAInterim show a small negative value, while the other simulations show positive values.

\subsection{Spatial wind patterns}

\subsubsection{Wind speed}

Figures 9 and 10 show the wind speed bias of the simulations with respect to SAFRAN and QuikSCAT, for days on which observation and simulation agree on an M/T situation being present or not. On non-M/T days (Fig. 9), all simulations show a more negative bias over the Mediterranean Sea close to the coast, than over the open sea. The bias of simulations with the smaller grid spacing is smaller in this area. Additionally, these runs show higher wind speeds than their coarser counterparts over large areas. On M/T days (Fig. 10), all simulations show a negative bias in the Gulf of Lion. The bias is larger at the sides of the main flow than at its center. Here, the runs with the smaller grid spacing show a smaller absolute bias. The bias is more negative on winter $\mathrm{M} / \mathrm{T}$ days than on summer $\mathrm{M} / \mathrm{T}$ days. At the same time, the observed winter $\mathrm{M} / \mathrm{T}$ wind speed is higher than the summer M/T wind speed (not shown). Interpolation effects in the valleys make it difficult to evaluate wind speeds. Therefore, processes in the valleys will be discussed in more detail in the next section. Furthermore, IPSL-WRF and UCLM-PROMES overestimate the wind 


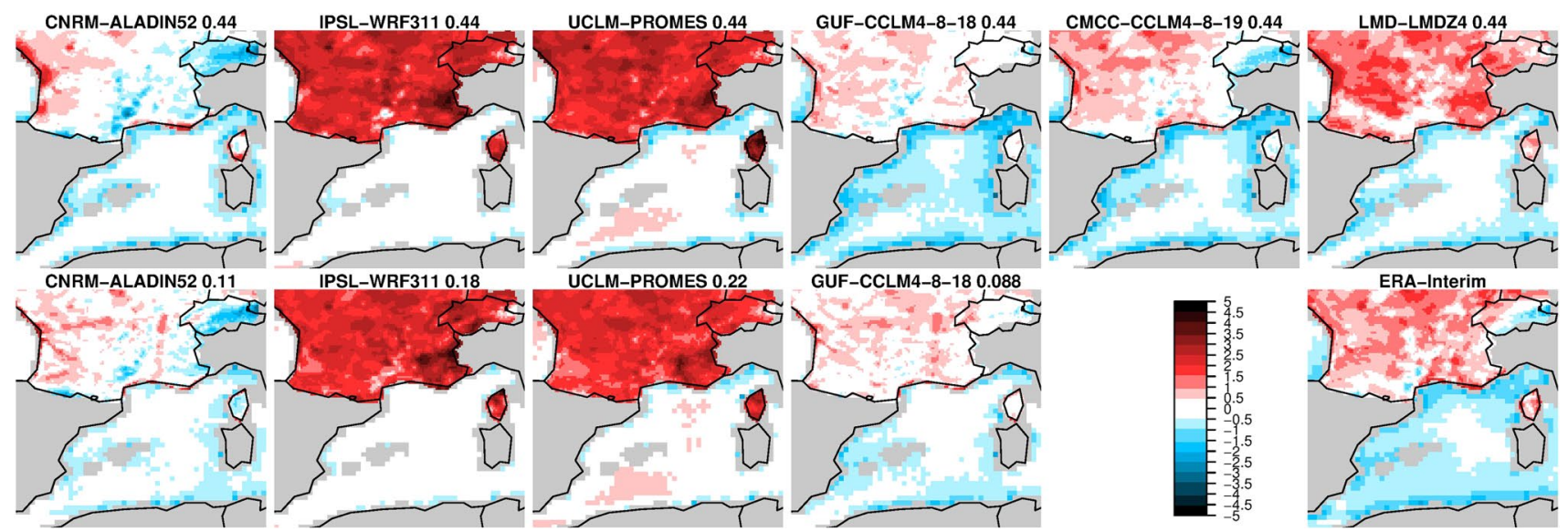

Fig. 9 Wind speed bias (m/s) for non-M/T days
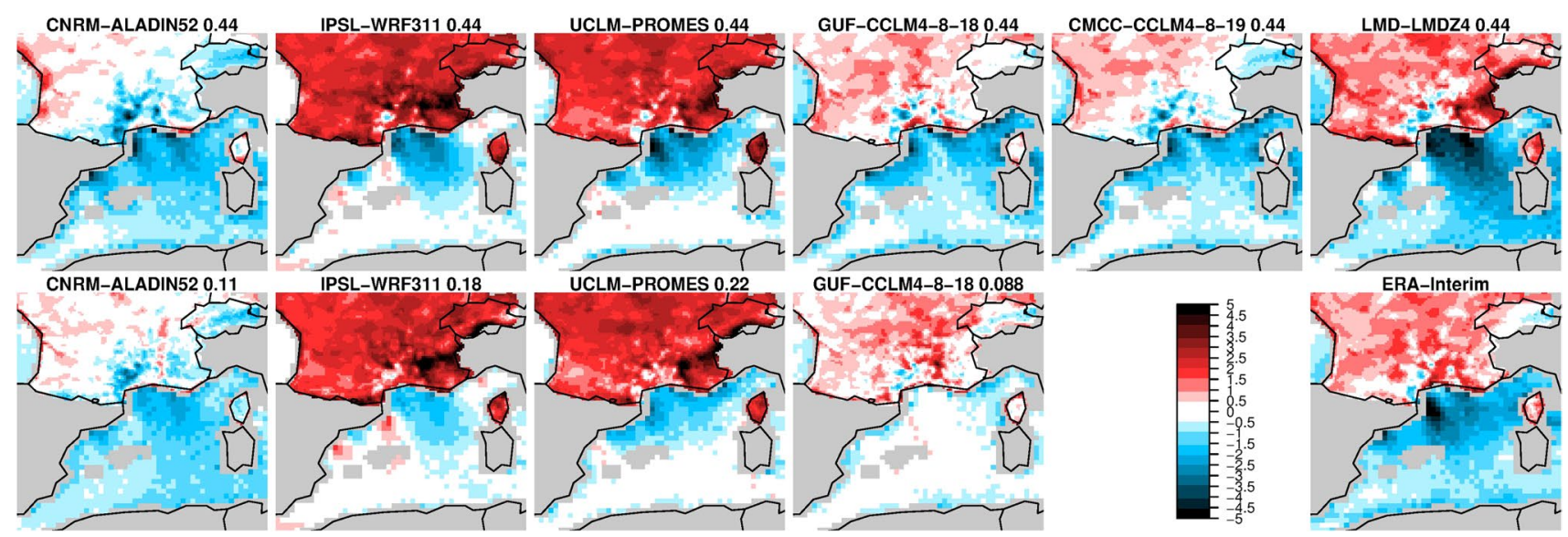

Fig. 10 Wind speed bias (m/s) for M/T days

speed over France, which makes a discussion of spatial patterns in comparison to the other models difficult.

Figure 11 shows the wind speed RMSEs of GUF-CCLM with respect to QuikSCAT and SAFRAN. The overall pattern is similar for all simulations. Over France, the RMSEs of IPSL-WRF and UCLM-PROMES are higher than those of the other simulations. Over the Mediterranean Sea, IPSL-WRF has the smallest RMSE, while UCLMPROMES has the largest (not shown). On M/T days, the highest RMSE occurs at the sides of the main flow-also the area of the largest bias - in the Gulf of Lion for all simulations. The simulations with smaller grid spacing have a smaller RMSE than their coarser counterparts.

\subsubsection{Wind direction}

Figures 12 and 13 show the wind direction biases. On non-M/T days (Fig. 12), IPSL-WRF, UCLM-PROMES, LMD-LMDZ, and ERA-Interim show a mainly positive wind direction bias (indicating that the wind comes from a direction that is too far clockwise). For CNRM-ALADIN, GUF-CCLM, and CMCC-CCLM, the absolute bias is smaller. On M/T days, the bias of CNRM-ALADIN and GUF-CCLM at $0.088^{\circ}$ grid spacing is slightly positive in the southwestern part of the Gulf of Lion. The bias of UCLM-PROMES and IPSL-WRF is positive in the north, and becomes more negative in the south. Figure 13 shows that the highest biases occur on the sides of the main flow and in the area where the Mistral enters the region over the Mediterranean Sea.

The surface wind direction RMSE of GUF-CCLM at $0.088^{\circ}$ grid spacing is shown in Fig. 14. The other simulations show similar RMSE patterns (not shown). On nonM/T days, the RMSE does not have much structure. On $\mathrm{M} / \mathrm{T}$ days, the wind direction is reproduced better in the main flow area, but the RMSE increases compared to non$\mathrm{M} / \mathrm{T}$ days in the areas close to the Spanish coast. Table 6 shows the RMSE within the Gulf of Lion region for all 


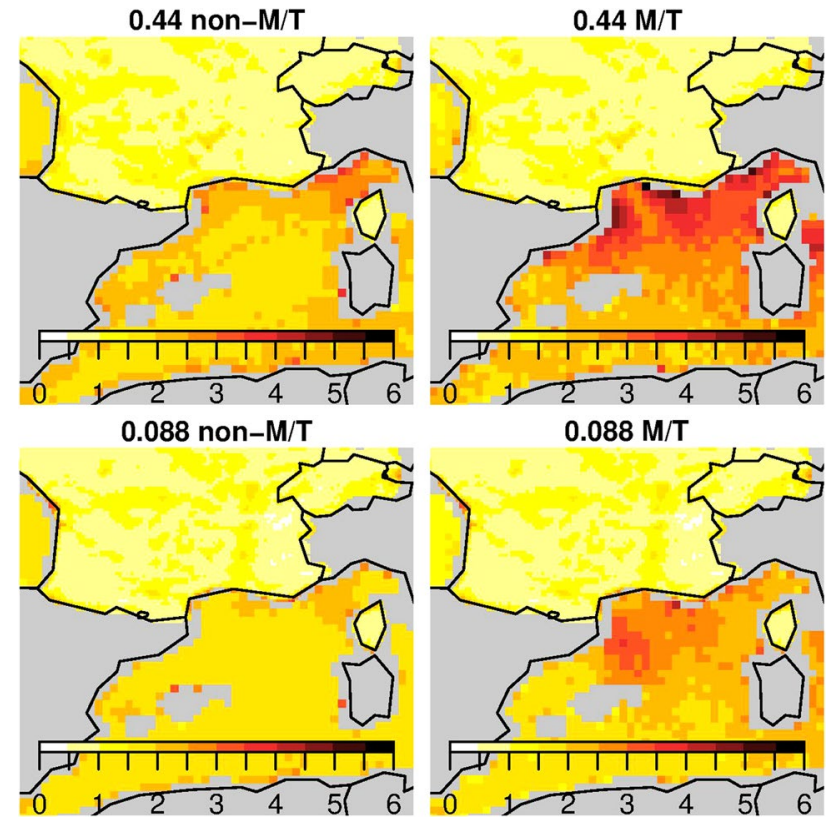

Fig. 11 Wind speed RMSE (m/s) for non-M/T and M/T days simulated with GUF-CCLM $4-8-18$ at 0.44 and $0.088^{\circ}$ grid spacing

the simulations. ERA-Interim has the lowest RMSE for both cases, followed by IPSL-WRF. UCLM-PROMES and LMD-LMDZ have higher RMSEs in both cases. The surface wind direction RMSE is smaller on M/T days than on non-M/T days for all the simulations.

\subsubsection{Influence of forcing data}

The influence of the forcing data can be estimated by comparing errors during days when ERA-Interim sea level pressure fields agree with observations on $\mathrm{M} / \mathrm{T}$ situations and days when the simulations sea level pressure patterns agree with observations. When taking into account all days of 2000-2008, the RMSE of ERA-Interim wind speed with respect to QuikSCAT in the Gulf of Lion region is $1.92 \mathrm{~m} / \mathrm{s}$. When considering only days on which ERA-Interim pressure fields and observed time series agree on $\mathrm{M} / \mathrm{T}$ situations, the RMSE stays at about the same value $(1.93 \mathrm{~m} / \mathrm{s})$. For GUF-CCLM at $0.088^{\circ}$ grid spacing, the results are similar: considering all days yields a wind speed RMSE of $2.01 \mathrm{~m} / \mathrm{s}$, considering ERA-Interim correct days yields $2.02 \mathrm{~m} / \mathrm{s}$, and considering days with correct model pressure fields yields $1.96 \mathrm{~m} / \mathrm{s}$. The other simulations behave similarly-they all show a smaller wind speed RMSE when considering only days on which the simulation $\mathrm{M} / \mathrm{T}$ situation agree with the observations than when considering days with correct ERAInterim $\mathrm{M} / \mathrm{T}$ situations.

When comparing the wind speed RMSE of each simulation of days with $\mathrm{M} / \mathrm{T}$ situations correctly predicted by ERA-Interim $\left(R M S E_{E R A}\right)$ and by the simulations $\left(R M S E_{\text {sim }}\right)$, the influence of the forcing data can be estimated by the relative difference in RMSE between both sets of days:

$d_{r}=\frac{R M S E_{E R A}-R M S E_{s i m}}{R M S E_{E R A}}$

A positive value of $d_{r}$ indicates an improvement by choosing the days with correctly simulated $\mathrm{M} / \mathrm{T}$ situations instead of ERA-Interim M/T situations. The relative difference $d_{r}$ varies between $0.47 \%$ (IPSL-WRF $0.18^{\circ}$ ) and $4.03 \%$ (GUF-CCLM $0.44^{\circ}$ ) over the Mediterranean Sea. In the valley areas, $d_{r}$ varies between $-0.61 \%$ (IPSL-WRF $0.44^{\circ}$ ) and $1.94 \%\left(\right.$ GUF-CCLM $0.44^{\circ}$ ).

\subsection{Along-flow development}

\subsubsection{Wind speed}

Figure 15 shows the observed and simulated mean wind speeds along the wind track in the Tramontane and Mistral valleys and above the Mediterranean Sea (blue and
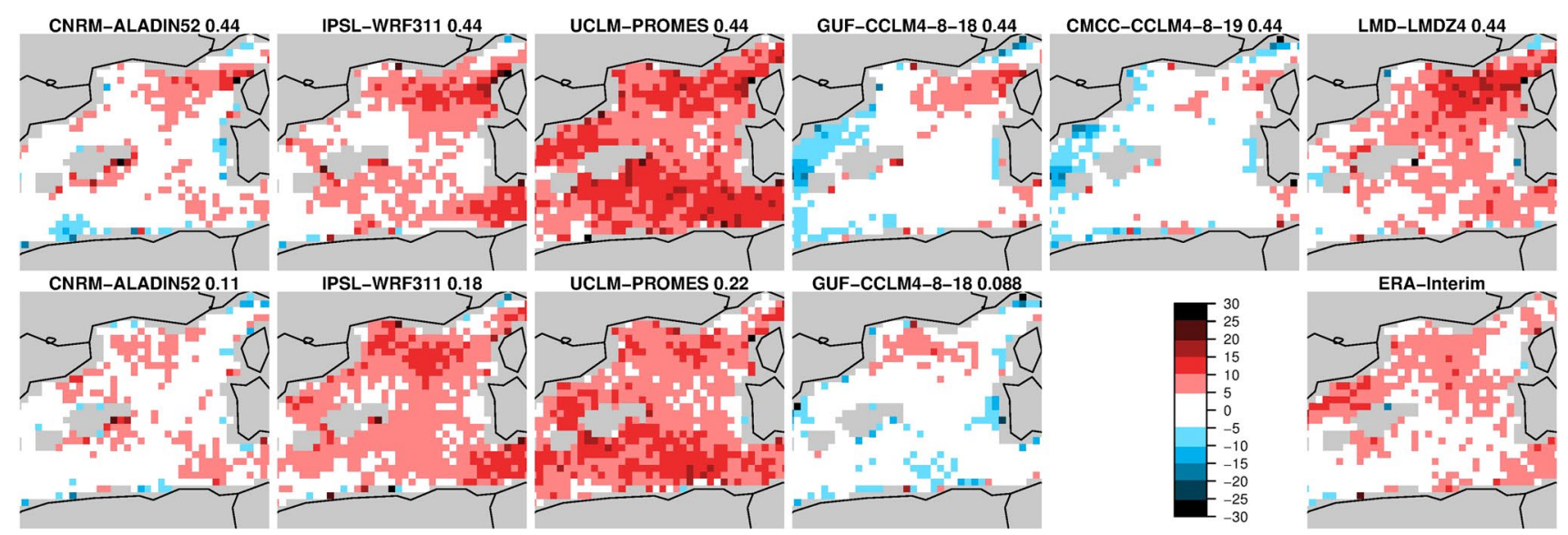

Fig. 12 Wind direction bias $\left({ }^{\circ}\right)$ for non-M/T days 


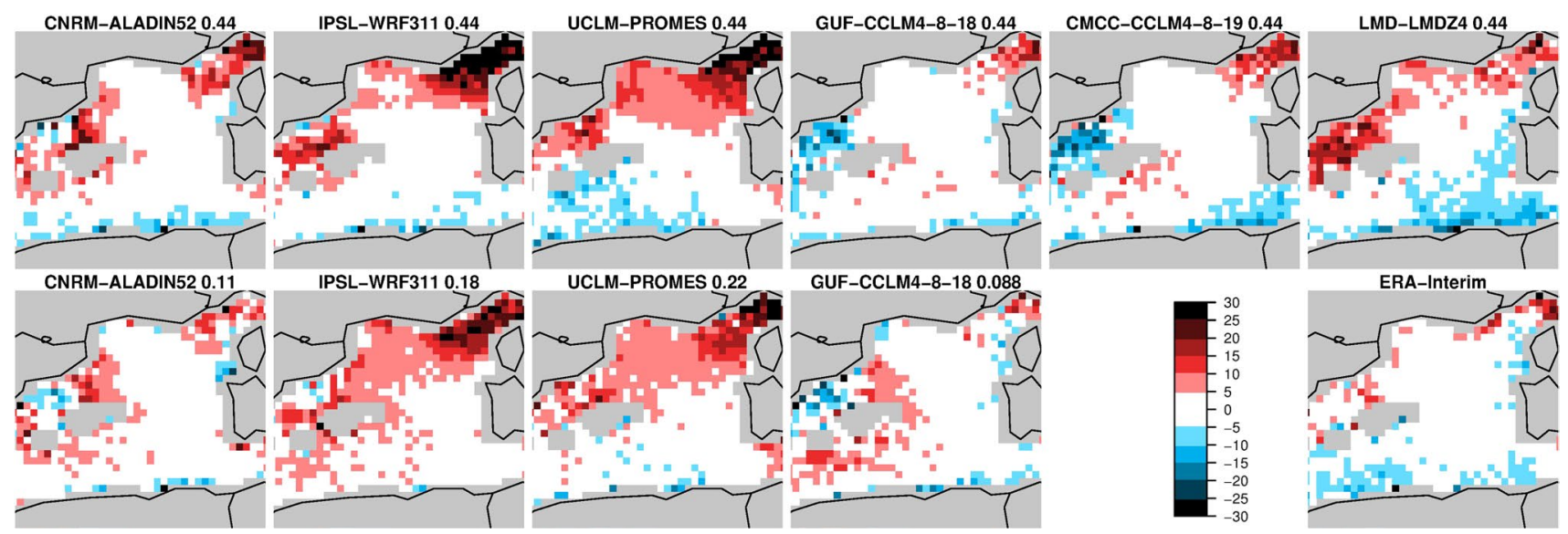

Fig. 13 Wind direction bias $\left({ }^{\circ}\right)$ for $\mathrm{M} / \mathrm{T}$ days
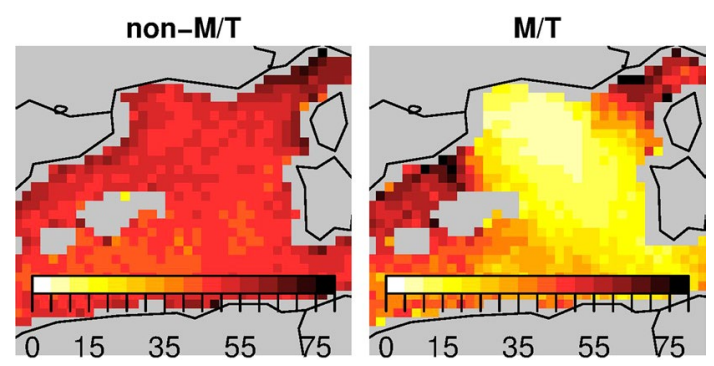

Fig. 14 Wind direction RMSE $\left({ }^{\circ}\right)$ of GUF-CCLM4-8-18 at $0.088^{\circ}$ grid spacing

gray areas in Fig. 1) on M/T days and non-M/T days. The observed Mistral wind speed (left column of Fig. 15) has two local maxima. The first local maximum is located in the narrowest part of the valley, about $180 \mathrm{~km}$ away from the coast, and the second local maximum is located $100 \mathrm{~km}$ away from the coast, where the valley opens. None of the simulations is able to reproduce both maxima. All simulations show an increase in wind speed close to the constriction, but most of the simulations miss the downstream decrease and the second local maximum. The Tramontane (middle column of Fig. 15) accelerates more continuously until the observed wind speed reaches $6-7 \mathrm{~m} / \mathrm{s}$. In both valleys, most simulations show a higher increase in wind speed than SAFRAN when approaching the coast, and almost reach the wind speed measured by QuikSCAT. UCLMPROMES and IPSL-WRF overestimate the wind speed in both valleys, but do not show an overestimation over the sea. Most simulations show a better agreement with the observations than ERA-Interim. Above the Mediterranean Sea (right column of Fig. 15), the observed wind speed is higher, reaching almost $12 \mathrm{~m} / \mathrm{s}$ at a distance of $100-300 \mathrm{~km}$ away from the coast on M/T days. All simulations except GUF-CCLM at $0.088^{\circ}$ grid spacing underestimate the wind
Table 6 RMSE of wind direction $\left({ }^{\circ}\right)$ in the Gulf of Lion region

\begin{tabular}{llll}
\hline Model & Grid $\left({ }^{\circ}\right)$ & Non-M/T & M/T \\
\hline CNRM-ALADIN & 0.44 & 50.02 & 27.81 \\
& 0.11 & 48.88 & 28.93 \\
IPSL-WRF & 0.44 & 37.70 & 24.28 \\
& 0.18 & 37.15 & 25.96 \\
UCLM-PROMES & 0.44 & 54.60 & 29.00 \\
GUF-CCLM & 0.22 & 52.42 & 28.40 \\
& 0.44 & 52.01 & 26.68 \\
CMCC-CCLM & 0.088 & 49.83 & 26.08 \\
LMD-LMDZ & 0.44 & 51.68 & 27.66 \\
ERA-Interim & 0.44 & 57.57 & 33.00 \\
\hline
\end{tabular}

speed over the Mediterranean Sea on M/T days as well as on non-M/T days, but are able to reproduce the overall shape of fetch dependence. All simulations except LMDLMDZ show better agreement with QuikSCAT than ERAInterim, which also underestimates the wind speed.

Figure 16 shows the RMSE of simulated wind speed with SAFRAN and QuikSCAT as reference. The highest RMSEs of IPSL-WRF, UCLM-PROMES, and GUFCCLM at $0.088^{\circ}$ grid spacing in the Mistral valley are located $140 \mathrm{~km}$ away from the coast at the position of a local minimum in the observed wind speed. The RMSE is also higher in the valleys for UCLM-PROMES and IPSLWRF than the other models. Above the Mediterranean Sea, RMSE decreases with increasing distance to the coast, and reaches values close to $2 \mathrm{~m} / \mathrm{s}$ on non-M/T days. Meanwhile, on M/T days, the RMSE is higher for all simulations.

\subsubsection{Wind direction}

Figure 17 shows the fetch dependence of the wind direction bias. The bias shows a different fetch-dependent behavior 

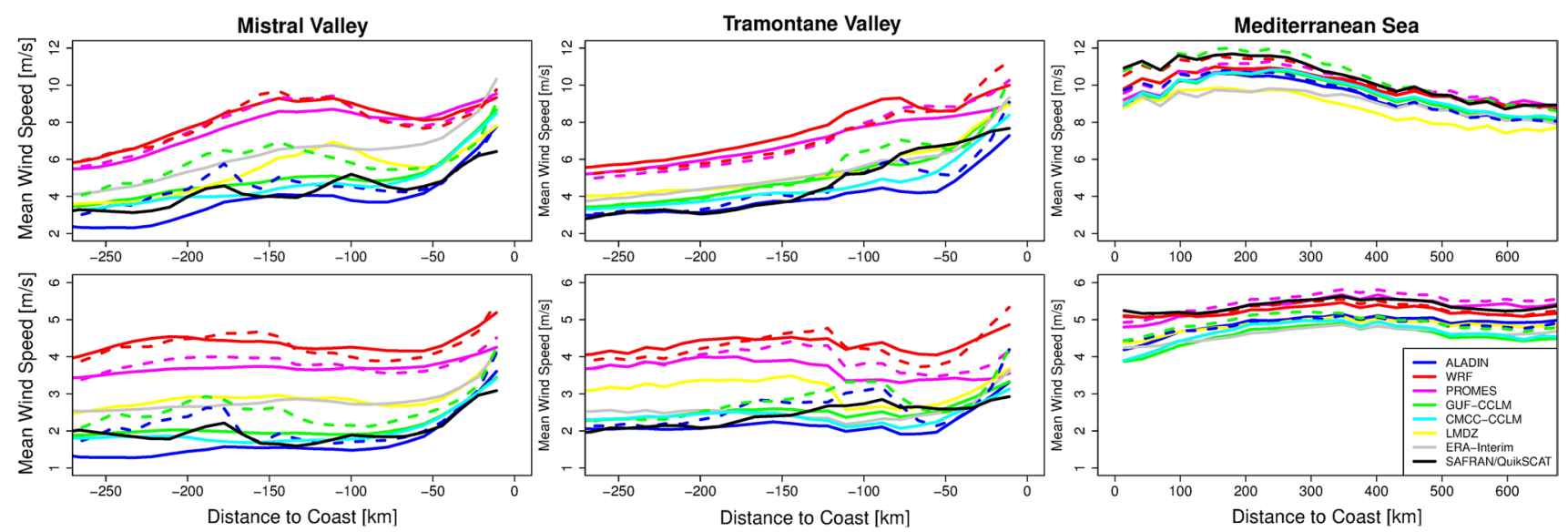

Fig. 15 Mean SAFRAN/QuikSCAT and simulated wind speed $(\mathrm{m} / \mathrm{s})$ in Mistral (left column) and Tramontane (middle column) valleys and above the Mediterranean Sea (right column) on M/T days (upper row) and non-M/T days (lower row)
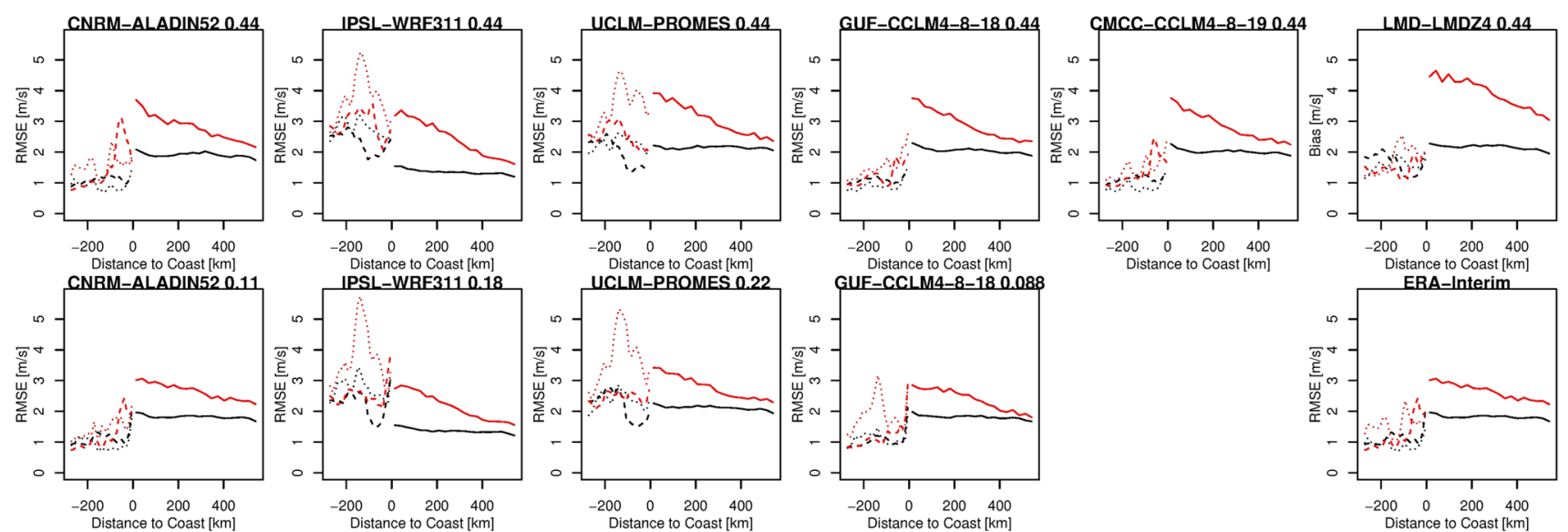

Fig. 16 Wind speed RMSE (m/s) as function of distance to the coast. On M/T days (red) and non-M/T days (black) in the Mistral valley (dotted line) and Tramontane valley (dashed line), as well as over the Mediterranean Sea (solid line)

on $\mathrm{M} / \mathrm{T}$ and non-M/T days. To quantify the development of wind direction bias, a linear fit is employed. Table 7 shows the parameters of the linear fit

$\beta(x)=\beta_{0}+a \cdot$ fetch.

On non-M/T days, the fit function shows a positive slope $a$ (indicating a change from counterclockwise to clockwiserotated wind bias) for most simulations. On M/T days, the slope is negative for all simulations (indicating a change from clockwise to counterclockwise-rotated wind). The intercept $\beta_{0}$ varies strongly between simulations. On $\mathrm{M} / \mathrm{T}$ days, all simulations show a positive intercept, with UCLMPROMES and IPSL-WRF reaching values greater than $10^{\circ}$.

Figure 18 shows the fetch dependence of the wind direction RMSE for GUF-CCLM. All simulations within this study show a similar dependence on fetch (not shown). The RMSE on non-M/T days is higher than on M/T days for all simulations. The RMSE on M/T days decreases strongly with increasing fetch for distances up to $250 \mathrm{~km}$ away from the coast, but does not get much better than $20^{\circ}$.

\section{Discussion}

The results presented in the previous section are discussed here. Three types of error sources are identified: large scale pressure patterns, valley effects, and effects over the Mediterranean Sea. Furthermore, the influence of grid spacing is discussed.

\subsection{Large-scale sea level pressure patterns}

ERA-Interim shows an agreement of $82 \%$ with the observations' M/T situations, which can be explained by the fact 

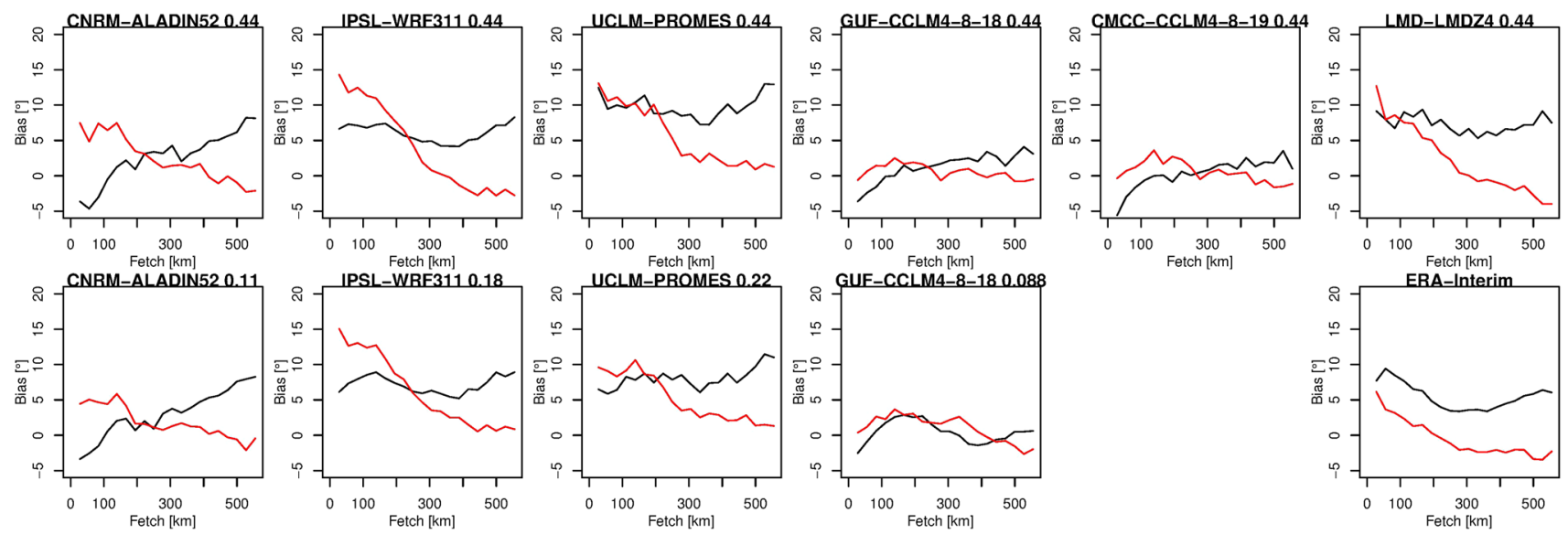

Fig. 17 Wind direction bias $\left({ }^{\circ}\right)$ as function of fetch. See Fig. 16 for legend
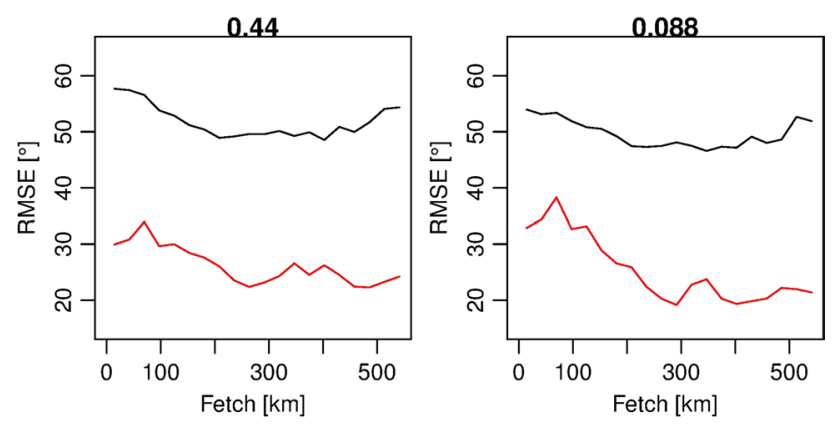

Fig. 18 Wind direction RMSE $\left({ }^{\circ}\right)$ as function of fetch for GUFCCLM 4-8-18 simulations with 0.44 and $0.088^{\circ}$ grid spacing. See Fig. 16 for legend

Table 7 Fit parameters, intercept $\left(\beta_{0}\right)$ and slope $(a)$, of wind direction bias (Fig. 17)

\begin{tabular}{|c|c|c|c|c|c|}
\hline \multirow[t]{2}{*}{ Model } & \multirow[t]{2}{*}{ Grid $\left({ }^{\circ}\right)$} & \multicolumn{2}{|c|}{ Non-M/T } & \multicolumn{2}{|l|}{$\mathrm{M} / \mathrm{T}$} \\
\hline & & $\beta_{0}\left(^{\circ}\right)$ & $\mathrm{a}\left({ }^{\circ} / 100 \mathrm{~km}\right)$ & $\beta_{0}\left(^{\circ}\right)$ & $\mathrm{a}\left({ }^{\circ} / 100 \mathrm{~km}\right)$ \\
\hline \multirow{2}{*}{$\begin{array}{l}\text { CNRM- } \\
\text { ALADIN }\end{array}$} & 0.44 & -2.90 & +2.01 & +7.49 & -1.84 \\
\hline & 0.11 & -2.39 & +1.96 & +5.21 & -1.22 \\
\hline \multirow[t]{2}{*}{ IPSL-WRF } & 0.44 & +6.44 & -0.12 & +13.72 & -3.58 \\
\hline & 0.18 & +7.09 & +0.02 & +14.30 & -2.96 \\
\hline \multirow{2}{*}{$\begin{array}{l}\text { UCLM- } \\
\text { PROMES }\end{array}$} & 0.44 & +9.49 & +0.11 & +12.01 & -2.38 \\
\hline & 0.22 & +6.44 & +0.58 & +10.29 & -1.87 \\
\hline \multirow{2}{*}{$\begin{array}{l}\text { GUF- } \\
\text { CCLM }\end{array}$} & 0.44 & -1.68 & +1.06 & +1.51 & -0.33 \\
\hline & 0.088 & +0.97 & -0.19 & +3.32 & -0.83 \\
\hline $\begin{array}{l}\text { CMCC- } \\
\text { CCLM }\end{array}$ & 0.44 & -2.53 & +1.03 & +2.22 & -0.60 \\
\hline $\begin{array}{l}\text { LMD- } \\
\text { LMDZ }\end{array}$ & 0.44 & +8.01 & -0.26 & +9.96 & -2.82 \\
\hline $\begin{array}{l}\text { ERA- } \\
\text { Interim }\end{array}$ & & +6.92 & -0.52 & +3.56 & -1.46 \\
\hline
\end{tabular}

that ERA-Interim was used as training data for the Bayesian network employed in the classification algorithm. ERAInterim achieves less than $100 \%$ of correctly predicted days, which could partly be explained by the fact that not all EOFs were used for the classification algorithm to eliminate noise. This leads to loss of information needed to reach a perfect score. Additionally, errors in station measurements can cause ambiguities in the training data. The very small number of cases (66 days) in the training data set could explain the low percentage of correctly modeled Mistral-only days. Even though more training data are available for Tramontane-only cases, their percentage of correctly predicted days is lower than that of $\mathrm{M} / \mathrm{T}$ and non$\mathrm{M} / \mathrm{T}$ cases. This could be due to more complex sea level pressure patterns during the Tramontane-only cases. The effect of over training the Bayesian network is unlikely to be present because increasing the number of training days did not reduce the number of correctly predicted days.

When the number of correctly reproduced days from the training data (2695 days) is used as reference, the simulations predict more than $90 \%$ of these days correctly. All models are therefore able to reproduce the M/T permitting patterns in most cases when ERA-Interim is used as the driving model. Besides ERA-Interim, IPSL-WRF has the highest number of days with correctly represented M/T patterns. It is the only model included in this study that is nudged to ERA-Interim over the planetary boundary layer for temperature, humidity and wind, and therefore has an advantage in terms of large-scale pressure fields.

\subsection{Effects in the valleys}

A possible source of errors in the valleys is the interpolations between valley and mountain grid cells, especially 
in narrow parts of the valley, for the simulations. The high wind speeds over France in IPSL-WRF simulations could be due to the Yonsei University (YSU) parameterization (Hong et al. 2006) used in WRF 3.1.1. Draxl et al. (2014) showed that WRF 3.1.1 with YSU tends to produce wind profiles typical for neutral conditions in the majority of cases. This leads to larger wind speed biases over land than over the sea, where neutral conditions occur more often. UCLM-PROMES also features a positive wind bias over land surfaces in both simulations, which has been found in other areas as well (Domínguez et al. 2010).

Mistral wind speeds show two local maxima where several hydraulic jumps have been observed in the lower Rhône valley (Drobinski et al. 2005). In the Tramontane flow, a hydraulic jump has been observed very close to the coast (Drobinski et al. 2001). At the location of a hydraulic jump, the wind speed drops rapidly. This effect is not represented neither in the regional climate simulations nor in ERA-Interim. Nevertheless, most simulations perform better than ERA-Interim in the valley areas.

\subsection{Effects over the Mediterranean Sea}

The RMSE of wind speed over the Mediterranean Sea could be reduced in most simulations by choosing only days with correctly predicted $\mathrm{M} / \mathrm{T}$ pressure patterns. Therefore, the spatial patterns over the Mediterranean Sea can be evaluated in greater detail when regarding only those days.

When the wind enters the region over the Mediterranean Sea, it shows a negative bias in all simulations. Accadia et al. (2007) and Ruti et al. (2008) found QuikSCAT to show higher wind speeds than observations from two buoys in the Gulf of Lion area. Therefore, part of the simulation bias could be explained by an overestimation of wind speed by QuikSCAT. Even simulations with a high overestimation of land surface wind speed do not overestimate surface wind speed over the Mediterranean Sea. Indeed, the sea surface wind speed is underestimated in those models as well. This hints that the simulations need several grid points to adjust to the situation above the sea surface. The effects at the coast are not yet understood. Since QuikSCAT observations are not available at the coast, but only at a distance of $25-50 \mathrm{~km}$, the wind speed change at the coast cannot be evaluated.

From the Charnock formula one might expect that smaller $\alpha$ values lead to higher wind speeds, but the wind speed bias does not only depend on the roughness length parameterization used. In the area of interest in this study, the $0.44^{\circ}$ simulations show no clear dependence of the bias on the $\alpha$ value. GUF-CCLM $(\alpha=0.0123)$ e.g. shows a by $-0.22 \mathrm{~m} / \mathrm{s}$ stronger bias than IPSL-WRF $(\alpha=0.0 .185)$, while the bias of CNRM-ALADIN ( $\alpha=0.021)$ is even more negative than that of GUF-CCLM by $-0.25 \mathrm{~m} / \mathrm{s}$. Edelmann (2015) tested the influence of roughness length parameterization on wind speed in GUF-CCLM at $0.088^{\circ}$ grid spacing. The bias of wind speed in the Gulf of Lion area was found to change by up to $0.5 \mathrm{~m} / \mathrm{s}$ for different versions of the Charnock formula, which is smaller than the overall bias over the Mediterranean Sea.

In all models, the main flow area of Mistral and Tramontane seems to be too narrow close to the coast. Errors are higher close to the Gulf of Lion coast than in the main flow area. When taking into account that QuikSCAT shows higher wind speeds than the buoy in the Gulf of Lion, these spatial patterns are robust (tested with a wind speed dependent QuikSCAT bias, not shown). Close to the eastern coast of the Gulf of Lion, intensified cooling has been observed during Mistral events and in coupled simulations (Small et al. 2012; Schaeffer et al. 2011). Renault et al. (2012) studied a Tramontane event in coupled simulations and found a decreasing sea surface temperature in the western part of the Gulf of Lion. Correct sea surface temperatures are important forcing data for the climate simulations. On one hand, sea surface temperature influences the momentum mixing of the atmospheric boundary layer, and therefore the wind speed. On the other hand, correct wind speed simulations are required to simulate the sea surface cooling during $\mathrm{M} / \mathrm{T}$ events in coupled simulations (Chelton et al. 2004; Lebeaupin Brossier and Drobinski 2009).

During M/T days, all simulations show a positive wind direction bias close to the coast and a negative slope in the fetch-dependent linear fit. This indicates wind that is rotated too far clockwise close to the coast, which turns in a counterclockwise direction while traveling over the Mediterranean Sea. About $220 \mathrm{~km}$ away from the coast, all models reach a wind direction RMSE close to the accuracy of the reference QuikSCAT product. Since the wind speed above the Mediterranean Sea is underestimated compared to QuikSCAT, the wind direction that is rotated too far clockwise is unlikely to be caused by Coriolis effects alone. The orographic features of the region (the Alps, Massif Central, and Pyrenees) also are important, and influence the wind direction. Giles (1977) stated that the Coanda effect causes the Mistral to stay attached to the Alps rather than blow straight over the Mediterranean Sea. This also changes the wind direction, causing the direction of gusts in the time series in Table 1 to change from north in the valley and plain stations to west and northwest at the easterly coastal stations Toulon and Cap Cepet. The erroneous simulation of the Mistral and Tramontane's attachment to the mountain ranges might also cause the too narrow main flow area in the Gulf of Lion. 


\subsection{Influence of grid spacing}

The higher resolution runs perform better in simulating small scale phenomena, such as the orographic features in mountainous areas. Thus, higher resolution simulations reach higher wind speeds in orography-induced winds (Mass et al. 2002; Louka et al. 2008). This effect is present in the CNRM-ALADIN and GUF-CCLM simulations, where higher resolution simulations show higher wind speeds than the simulations with coarser resolution. Simulations with smaller grid spacing also show higher wind speeds over the Mediterranean Sea, and therefore smaller biases. They also adjust faster to the higher wind speeds and show less pronounced errors at the borders of the main flow.

\section{Summary and conclusion}

The goal of this study was to evaluate five regional climate models (ALADIN, WRF, PROMES, CCLM, and LMDZ) in terms of the Mistral and Tramontane. The focus was on the effects when a Mistral and/or Tramontane event is simulated. Therefore, days on which simulated sea level pressure fields show a Mistral and Tramontane permittingpattern were identified. After excluding errors due to the large-scale pressure fields, further error sources could be identified.

The results show that all five regional climate models used in this survey are able to correctly simulate Mistral and Tramontane situations $74-82 \%$ of the time. Most models show smaller wind speed biases than ERA-Interim in the Mistral and Tramontane areas of southern France. However, the modeling of effects in the valleys is still erroneous. Wind speed changes in areas with small-scale orographic features are difficult to reproduce in simulations. During Mistral and Tramontane events, most simulations underestimate wind speed over the Mediterranean Sea, but show smaller biases than ERA-Interim. The bias is strongest at the borders of the main flow. All simulations of this study show a clockwise wind direction bias during Mistral and Tramontane events. Higher resolution simulations $\left(0.088^{\circ}-0.22^{\circ}\right.$ grid spacing $)$ show smaller biases than their $0.44^{\circ}$ counterparts.

This leads to the conclusion that regional climate models are mostly able to simulate Mistral and Tramontane events at the correct dates, and with smaller biases than ERA-Interim. When the large scale is represented well in the driving model, regional climate models can simulate Mistral and Tramontane. Higher resolution simulations provide better results in the valleys, but the major improvement obtained by increasing the resolution occurs over the sea. This effect is not yet understood. To correct the wind speed underestimation over the sea, especially at the borders of the main flow, the reciprocal interference of the sea surface temperature and wind speed and the influence of the Coanda effect should be investigated in further studies.

Acknowledgments This work is part of the Med-CORDEX initiative (www.medcordex.eu) supported by the HyMeX programme (www.hymex.org). This work is a contribution to the HyMeX program (HYdrological cycle in The Mediterranean EXperiment) through INSU-MISTRALS support and the MEDCORDEX program (COordinated Regional climate Downscaling EXperiment - Mediterranean region). The simulations used in this work were downloaded from the Med-CORDEX database. Gust time series were provided by Valérie Jacq, Météo-France. GUF simulations were performed at DKRZ and LOEWE-CSC. GUF acknowledges support from Senckenberg BiK-F and by the German Federal Ministry of Education and Research (BMBF) under Grant MiKlip: Regionalization 01LP1518C. This research has received funding from the French National Research Agency (ANR) projects REMEMBER (contract ANR-12SENV-001). It was supported by the IPSL group for regional climate and environmental studies, with granted access to the HPC ressources of GENCI/IDRIS (under allocation i2011010227). UCLM contribution has been partially funded by the Spanish Government and the European Regional Development Fund, through grants CGL200766440-C04-02, CGL2010-18013 and CGL2013-47261-R.

Open Access This article is distributed under the terms of the Creative Commons Attribution 4.0 International License (http://creativecommons.org/licenses/by/4.0/), which permits unrestricted use, distribution, and reproduction in any medium, provided you give appropriate credit to the original author(s) and the source, provide a link to the Creative Commons license, and indicate if changes were made.

\section{References}

Accadia C, Zecchetto S, Lavagnini A, Speranza A (2007) Comparison of $10-\mathrm{m}$ wind forecasts from a regional area model and QuikSCAT scatterometer wind observations over the mediterranean sea. Mon Weather Rev 135(5):1945-1960. doi:10.1175/ MWR3370.1

Amante C, Eakins B (2009) ETOPO1 1 arc-minute global relief model: Procedures, data sources and analysis. NOAA Technical Memorandum NESDIS NGDC-24, doi:10.7289/V5C8276M

Andreas EL (2004) Spray stress revisited. J Phys Oceanogr 34:1429-1439

Bastin S, Drobinski P, Guénard V, Caccia JL, Campistron B, Dabas AM, Delville P, Reitebuch O, Werner C (2006) On the interaction between sea breeze and summer mistral at the exit of the rhône valley. Mon Weather Rev 134(6):1647-1668. doi:10.1175/ MWR3116.1

Béranger K, Drillet Y, Houssais MN, Testor P, Bourdallé-Badie R, Alhammoud B, Bozec A, Mortier L, Bouruet-Aubertot P, Crépon M (2010) Impact of the spatial distribution of the atmospheric forcing on water mass formation in the mediterranean sea. $\mathbf{J}$ Geophys Res Oceans 115(C12). doi:10.1029/2009JC005648

Berthou S, Mailler S, Drobinski P, Arsouze T, Bastin S, Béranger K , Lebeaupin-Brossier C (2014) Prior history of Mistral and Tramontane winds modulates heavy precipitation events in southern France. Tellus A 66. doi:10.3402/tellusa.v66.24064

Berthou S, Mailler S, Drobinski P, Arsouze T, Bastin S, Béranger K, Lebeaupin-Brossier C (2015) Sensitivity of an intense rain 
event between atmosphere-only and atmosphere-ocean regional coupled models: 19 september 1996. Q J R Meteorol Soc 141(686):258-271. doi:10.1002/qj.2355

Cavaleri L, Fox-Kemper B, Hemer M (2012) Wind waves in the coupled climate system. Bull Am Meteorol Soc 93:1651-1661

Charnock H (1955) Wind stress on a water surface. Q J R Meteorol Soc 81(350):639-640. doi:10.1002/qj.49708135027

Chelton DB, Schlax MG, Freilich MH, Milliff RF (2004) Satellite measurements reveal persistent small-scale features in ocean winds. Science 303(5660):978-983

Colin J, Déqué M, Radu R, Somot S (2010) Sensitivity study of heavy precipitation in limited area model climate simulations: influence of the size of the domain and the use of the spectral nudging technique. Tellus A 62(5):591-604. doi:10.1111/j.1600-0870.2010.00467.x

Dee DP, Uppala SM, Simmons AJ, Berrisford P, Poli P, Kobayashi S, Andrae U, Balmaseda MA, Balsamo G, Bauer P, Bechtold P, Beljaars ACM, van de Berg L, Bidlot J, Bormann N, Delsol C, Dragani R, Fuentes M, Geer AJ, Haimberger L, Healy SB, Hersbach H, Hólm EV, Isaksen L, Kållberg P, Köhler M, Matricardi M, McNally AP, Monge-Sanz BM, Morcrette JJ, Park BK, Peubey C, de Rosnay P, Tavolato C, Thépaut JN, Vitart F (2011) The ERA-interim reanalysis: configuration and performance of the data assimilation system. Q J R Meteorol Soc 137(656):553597. doi:10.1002/qj.828

Domínguez M, Gaertner M, de Rosnay P, Losada T (2010) A regional climate model simulation over west africa: parameterization tests and analysis of land-surface fields. Clim Dyn 35(1):249-265. doi:10.1007/s00382-010-0769-3

Doms G, J Foerstner EH, Herzog HJ, Mironov D, Raschendorfer M, Reinhardt T , Ritter B, Schrodin R, Schulz JP, Vogel G (2011) A Description of the Nonhydrostatic Regional COSMO Model Part II: Physical Parameterization, Deutscher Wetterdienst, Offenbach, Germany

Donelan MA, Dobson FW, Smith SD, Anderson RJ (1993) On the dependence of sea surface roughness on wave development. J Phys Oceanogr 23(9):2143-2149. doi:10.1175/1520-0485(1993)023<2143:OTD OSS $>2.0 . \mathrm{CO} ; 2$

Dorman CE, Mejia JF, Koračin D (2013) Impact of us west coastline inhomogeneity and synoptic forcing on winds, wind stress, and wind stress curl during upwelling season. J Geophys Res Oceans 118(9):4036-4051

Draxl C, Hahmann AN, Peña A, Giebel G (2014) Evaluating winds and vertical wind shear from weather research and forecasting model forecasts using seven planetary boundary layer schemes. Wind Energy 17(1):39-55. doi:10.1002/we.1555

Drobinski P, Flamant C, Dusek J, Flamant P, Pelon J (2001) Observational evidence and modelling of an internal hydraulic jump at the atmospheric boundary-layer top during a tramontane event. Bound Layer Meteorol 98(3):497-515. doi:10.1023/A:1018751311924

Drobinski P, Bastin S, Guenard V, Caccia JL, Dabas A, Delville P, Protat A, Reitebuch O, Werner C (2005) Summer mistral at the exit of the rhône valley. Q J R Meteorol Soc 131(605):353-375. doi:10.1256/qj.04.63

Drobinski P, Ducrocq V, Alpert P, Anagnostou E, Béranger K, Borga M, Braud I, Chanzy A, Davolio S, Delrieu G, Estournel C, Filali Boubrahmi N, Font J, Grubišić V, Gualdi S, Homar V, Ivančan Picek B, Kottmeier C, Kotroni V, Lagouvardos K, Lionello P, Llasat MC, Ludwig W, Lutoff C, Mariotti A, Richard E, Romero R, Rotunno R, Roussot O, Ruin I, Somot S, Taupier-Letage I, Tintore J, Uijlenhoet R, Wernli H (2014) HyMeX: a 10-year multidisciplinary program on the mediterranean water cycle. Bull Am Meteorol Soc 95:1063-1082

Edelmann B (2015) Dependence of COSMO-CLM simulated wind on wind stress parameterisation in the gulf of lion. Master's thesis, Goethe Universität Frankfurt
Flaounas E, Drobinski P, Vrac M, Bastin S, Lebeaupin-Brossier C, Stéfanon M, Borga M, Calvet JC (2013) Precipitation and temperature space-time variability and extremes in the Mediterranean region: evaluation of dynamical and statistical downscaling methods. Clim Dyn 40(11-12):2687-2705. doi:10.1007/s00382012-1558-y. https://hal.archives-ouvertes.fr/hal-00750590

Georgelin M, Richard E, Petitdidier M, Druilhet A (1994) Impact of subgrid-scale orography parameterization on the simulation of orographic flows. Mon Weather Rev 122:1509-1522. doi:10.1175/1520-0493(1994)122<1509:IOSSOP>2.0.CO;2

Giles B (1977) Fluidics, the coanda effect, and some orographic winds. Archiv für Meteorologie, Geophysik und Bioklimatologie, Serie A 25(3):273-279. doi:10.1007/BF02321800

Golbraikh E, Shtemler YM (2013) Drag coefficient for the air-sea exchange in hurricane conditions. arXiv:1304.0938

Guenard V, Drobinski P, Caccia JL, Campistron B, Bench B (2005) An observational study of the mesoscale mistral dynamics. Bound Layer Meteorol 115(2):263-288. doi:10.1007/ s10546-004-3406-z

Herrmann M, Somot S, Calmanti S, Dubois C, Sevault F (2011) Representation of daily wind speed spatial and temporal variability and intense wind events over the mediterranean sea using dynamical downscaling : impact of the regional climate model configuration. Nat Hazards Earth Syst Sci 11:1983-2001. doi:10.5194/nhess-11-1983-2011

Hong SY, Noh Y, Dudhia J (2006) A new vertical diffusion package with an explicit treatment of entrainment processes. Mon Weather Rev 134:2318-2341

Hourdin F, Musat I, Bony S, Braconnot P, Codron F, Dufresne JL, Fairhead L, Filiberti MA, Friedlingstein P, Grandpeix JY, Krinner G, LeVan P, Li ZX, Lott F (2006) The LMDZ4 general circulation model: climate performance and sensitivity to parametrized physics with emphasis on tropical convection. Clim Dyn 27(7-8):787-813. doi:10.1007/s00382-006-0158-0

Jacq V, Albert P, Delorme R (2005) Le mistral, en 1925 et aujourd'hui : Le mistral - quelques aspects des connaissances actuelles. La Météorologie 50:30-38

Jiménez P, Dudhia J (2014) On the wind stress formulation over shallow waters in atmospheric models. Geosci Model Dev Discuss 7(6):9063-9077

Jungo P, Goyette S, Beniston M (2002) Daily wind gust speed probabilities over switzerland according to three types of synoptic circulation. Int J Climatol 22(4):485-499

Kothe S, Panitz HJ, Ahrens B (2014) Analysis of the radiation budget in regional climate simulations with COSMO-CLM for africa. Meteorol Z 23(2):123-141. doi:10.1127/0941-2948/2014/0527

Lange B, Højstrup J, Larsen S, Barthelmie R (2001) A fetch dependent model of sea surface roughness for offshore wind power utilisation. In: Proceedings of the European wind energy conference (Copenhagen 2001). Wip, Munich and Eta, Florenz, pp 830-833

Lawrence D, Slingo J (2004a) An annual cycle of vegetation in a GCM. part i: implementation and impact on evaporation. Clim Dyn 22(2-3):87-105. doi:10.1007/s00382-003-0366-9

Lawrence D, Slingo J (2004b) An annual cycle of vegetation in a GCM. part ii: global impacts on climate and hydrology. Clim Dyn 22(2-3):107-122. doi:10.1007/s00382-003-0367-8

Lebeaupin Brossier C, Drobinski P (2009) Numerical high-resolution air-sea coupling over the gulf of lions during two tramontane/mistral events. J Geophys Res Atmos. doi:10.1029/200 8JD011601

Louka P, Galanis G, Siebert N, Kariniotakis G, Katsafados P, Pytharoulis I, Kallos G (2008) Improvements in wind speed forecasts for wind power prediction purposes using kalman filtering. J Wind Eng Ind Aerodyn 96(12):2348-2362. doi:10.1016/j.jweia.2008.03.013

Lungu T, Dunbar S, Weiss B, Stiles B, Huddleston J, Callahan P, Shirtliffe G, Perry KL, Hsu C, Mears C, Wentz F, Smith D 
(2006) QuikSCAT science data product users manual version 3.0. Rep. D-18053, 97 pp., Jet Propulsion Laboratory

Mass CF, Ovens D, Westrick K, Colle BA (2002) Does increasing horizontal resolution produce more skillful forecasts? Bull Am Meteorol Soc 83(3):407-430

Potter H (2015) Swell and the drag coefficient. Ocean Dyn 65(3):375384. doi:10.1007/s10236-015-0811-4

Powell MD, Vickery PJ, Reinhold TA (2003) Reduced drag coefficient for high wind speeds in tropical cyclones. Nature 422(6929):279-283

Quintana-Seguí P, Le Moigne P, Durand Y, Martin E, Habets F, Baillon M, Canellas C, Franchisteguy L, Morel S (2008) Analysis of near-surface atmospheric variables: validation of the SAFRAN analysis over france. J Appl Meteorol Climatol 47(1):92-107

Renault L, Chiggiato J, Warner JC, Gomez M, Vizoso G, Tintoré J (2012) Coupled atmosphere-ocean-wave simulations of a storm event over the gulf of lion and balearic sea. J Geophys Res Oceans 117(C9). doi:10.1029/2012JC007924

Risien CM, Chelton DB (2006) A satellite-derived climatology of global ocean winds. Remote Sens Environ 105(3):221-236. doi:10.1016/j.rse.2006.06.017

Rockel B, Will A, Hense A (2008) The regional climate model COSMO-CLM (CCLM). Meteorol Z 17(4):347-348

Ruti P, Somot S, Giorgi F, Dubois C, Flaounas E, Obermann A, Dell'Aquila A, Pisacane G, Harzallah A, Lombardi E, Ahrens B, Akhtar N, Alias A, Arsouze T, Aznar R, Bastin S, Bartholy J, BérangerK Beuvier J, Bouffies-Cloché S, Brauch J, Cabos W, Calmanti S, Calvet JC, Carillo A, Conte D, Coppola E, Djurdjevic V, Drobinski P, Elizalde-Arellano A, Gaertner M, Galàn $\mathrm{P}$, Gallardo C, Gualdi S, Goncalves M, Jorba O, Jordà G, L'Heveder B, Lebeaupin-Brossier C, Li L, Liguori G, Lionello $\mathrm{P}$, Maciàs D, Nabat $\mathrm{P}$, Onol B, Raikovic B, Ramage K, Sevault F, Sannino G, Struglia M, Sanna A, Torma C, Vervatis V (2015) MED-CORDEX initiative for mediterranean climate studies. Bull Am Meteorol Soc. doi:10.1175/BAMS-D-14-00176.1

Ruti PM, Marullo S, D'Ortenzio F, Tremant M (2008) Comparison of analyzed and measured wind speeds in the perspective of oceanic simulations over the mediterranean basin: Analyses, QuikSCAT and buoy data. J Mar Syst 70(1-2):33-48
Schaeffer A, Garreau P, Molcard A, Fraunié P, Seity Y (2011) Influence of high-resolution wind forcing on hydrodynamic modeling of the gulf of lions. Ocean Dyn 61(11):1823-1844. doi:10.1007/ s10236-011-0442-3

Schmidtke H, Scherrer H (1997) Sturmschäden im Wald. Schlussbericht / NFP 31, vdf, Hochschulverlag AG an der ETH Zürich. https://books.google.de/books?id=3E7_klVnaTUC

Schott F, Visbeck M, Send U, Fischer J, Stramma L, Desaubies Y (1996) Observations of deep convection in the gulf of lions, northern mediterranean, during the winter of 1991/92. J Phys Oceanogr 26(4):505-524

Scutari M (2010) Learning bayesian networks with the bnlearn R package. J Stat Softw 35(3):1-22

Skamarock W, Klemp J, Dudhia J, Gill D, Barker D, Duda M, Huang X, Wang W, Powers J (2008) A description of the advanced research WRF version 3. Technical Report, NCAR

Small R, Carniel S, Campbell T, Teixeira J, Allard R (2012) The response of the ligurian and tyrrhenian seas to a summer mistral event: A coupled atmosphereocean approach. Ocean Model 48:30-44. doi:10.1016/j.ocemod.2012.02.003

Stéfanon M, Drobinski P, D'Andrea F, Lebeaupin-Brossier C, Bastin S (2014) Soil moisture-temperature feedbacks at meso-scale during summer heat waves over western europe. Clim Dyn 42(56):1309-1324. doi:10.1007/s00382-013-1794-9

von Storch H, Zwiers F (2001) Statistical analysis in climate research. Cambridge University Press. https://books.google.de/ books?id=_VHxE26QvXgC

Tsamardinos I, Brown LE, Aliferis CF (2006) The max-min hillclimbing bayesian network structure learning algorithm. Mach Learn 65(1):31-78. doi:10.1007/s10994-006-6889-7

Vidal JP, Martin E, Franchistéguy L, Baillon M, Soubeyroux JM (2010) A 50-year high-resolution atmospheric reanalysis over france with the safran system. Int J Climatol 30:1627-1644

Warrens MJ (2008) On association coefficients for $2 \times 2$ tables and properties that do not depend on the marginal distributions. Psychometrika 73(4):777-789 